Boletín de la Sociedad Geológica Mexicana

Volumen Conmemorativo del Centenario

Revisión de Algunas Tipologías de Depósitos Minerales en MéXico

Toмo LVIII, NÚM. 1, 2006, P. 161-181

\title{
Características geológicas y potencial metalogenético de los principales complejos ultramáficos-máficos de México
}

\author{
Luis Enrique Ortiz-Hernández, ${ }^{1, *}$, José Cruz Escamilla-Casas ${ }^{1}$, Kinardo Flores-Castro ${ }^{1}$, \\ Marius Ramírez-Cardona ${ }^{1}$, Otilio Acevedo-Sandoval ${ }^{2}$. \\ ${ }^{1}$ Centro de Investigaciones en Ciencias de la Tierra, Universidad Autónoma del Estado de Hidalgo. \\ Carretera Pachuca-Tulancingo km 4.5, 42184, Pachuca, Hidalgo, México. \\ ${ }^{2}$ Sección de Estudios de Posgrado e Investigación, ESIA-Unidad Ticomán. Instituto Politécnico Nacional. \\ Avenida Ticomán núm. 600, Col. San José Ticomán. Del. Gustavo A. Madero, C.P. 07340, México, D.F. \\ *leoh44@hotmail.com
}

\section{Resumen}

El consenso de los principales complejos ultramáficos-máficos (UM-M) en diez estados de la República Mexicana (Baja California, Baja California Sur, Sinaloa, Tamaulipas, Guanajuato, Guerrero, Estado de México, Puebla, Oaxaca y Chiapas) indica que su edad varía entre el Paleozoico y el Paleoceno, y que están asociados a diferentes contextos tectónicos, e. g. raíz de arco volcánico, ofiolita, cuenca oceánica, complejo de subducción y fragmento continental. La mayoría de los complejos UM-M ocurren en los terrenos tectonoestratigráficos Tahué y Náhuatl, y en menor proporción en los terrenos Cochimí, Yuma, Guachichil, Tepehuano, Mixteco, Cuicateco y Maya.

Los complejos UM-M más antiguos son los de Cañón del Novillo en Tamaulipas, formado posiblemente en un complejo de subducción. El Fuerte, Agua Caliente y Mazatlán en Sinaloa asociados a cuencas oceánicas (?), y Tehuitzingo-Tecomatlán en Puebla, que corresponde a una ofiolita de tipo zona de suprasubducción. Existen complejos UM-M del Triásico Superior-Jurásico Medio (Isla de Cedros y península de Vizcaíno, e Islas Margarita y Magdalena en Baja California Sur) con afinidad ofiolítica en un complejo de subducción, mientras que los complejos del Cretácico Inferior (Alisitos y Culiacán en Sinaloa, San Juan de Otates en Guanajuato, y Palmar Chico-San Pedro Limón en el Estado de México), son los más característicos y están asociados a las raíces de un arco magmático. Los complejos más recientes son los de Ojos Negros en Baja California (Cretácico Superior-Paleoceno), que representa parte de la raíz plutónica del batolito californiano, y las peridotitas de flogopita con afinidad kimberlítica de San Javier en Sinaloa (Mesozoico superior-Terciario temprano), que están asociadas a un fragmento continental subyacente a un arco magmático. En cuanto a los complejos restantes: Bacubirito, en Sinaloa, está asociado a una ofiolita desmembrada desarrollada en una cuenca oceánica. Cuicatlán-Concepción Pápalo, en Oaxaca, representa posiblemente un arco magmático intracontinental de corta vida. Los complejos UM-M de Guerrero (Las Ollas, Camalotito, Loma Baya y El Tamarindo) se asocian a raíces de arco intraoceánico en un complejo de subducción. Finalmente, los pequeños cuerpos UM-M de Motozintla en Chiapas constituyen fragmentos de la raíz de un arco magmático alojados en una zona de cizalla.

Estos complejos UM-M albergan mineralización no metálica desarrollada durante su alteración y/o metamorfismo (asbesto, talco y magnesita), y mineralización metálica producida mediante procesos magmáticos (cuerpos lenticulares alargados o pods de cromitita, diseminaciones de cobre, níquel y cobalto), y pueden contener asimismo trazas de minerales del grupo del platino.

Palabras clave: Rocas ultramáficas-máficas, características geológicas, potencial metalogenético, México. 


\begin{abstract}
The consensus of the major mafic-ultramafic complexes (UM-M) in ten states of the Mexican Republic (Baja California, Baja California Sur, Sinaloa, Tamaulipas, Guanajuato, Guerrero, Estado de Mexico, Puebla, Oaxaca, and Chiapas) indicates that their age ranges from Paleozoic to Paleocene and that are associated with diverse tectonic settings: e.g. root volcanic arc, ophiolite, oceanic basin, subduction complex, and continental fragment. The majority of the complexes occur in the following tectonostratigraphic terranes: Tahué and Náhuatl; and in less proportion in Cochimi, Yuma, Guachichil, Tepehuano, Mixteco, Cuicateco and Maya.

The older UM-M complexes are: in Tamaulipas, Cañon del Novillo (that probably constitutes a subduction complex); El Fuerte, Agua Caliente, and Mazatlan, in Sinaloa, which are associated with oceanic basins (?); and TehuitzingoTecomatlan, in Puebla, associated with a supra-subduction zone ophiolite. The Late Triassic-Middle Jurassic UM-M complexes (Isla de Cedros, Vizcaino Peninsula, and Isla Margarita and Magdalena in Baja California Sur) have ophiolitic affinity in a subduction complex. Early Cretaceous complexes (Alisitos and Culiacan, in Sinaloa; San Juan de Otates, in Guanajuato; and Palmar Chico-San Pedro Limon, in Estado de Mexico) are the most characteristic and are associated with a dismembered ophiolite developed in an oceanic basin. Among the remainder of the complexes are: Bacubirito, in Sinaloa, associated with a dismembered ophiolite developed in an oceanic basin; Cuicatlan-Concepcion Papalo, in Oaxaca, possibly represents a short living, intracontinental, magmatic arc.

The more recent complexes are: Ojos Negros, in Baja California (Late Cretaceous-Paleocene) and corresponds to the plutonic root of the Californian Batholith; and the micaceous peridotites with kimberlitic affinity of San Javier, in Sinaloa (Upper Mesozoic-Early Tertiary) that are associated with a continental fragment underlying a magmatic arc. The UM-M complexes in Guerrero (Las Ollas, Camalotito, Loma Baya y El Tamarindo) are associated with intraoceanic arc roots in a subduction complex. Finally, the small UM-M bodies of Motozintla, in Chiapas, constitute fragments of the root of a magmatic arc allocated in a shear zone.

These UM-M complexes host both, non-metallic mineralization developed during alteration and/or metamorphism (asbestos, talc, magnesite) and metallic mineralization produced after magmatic processes (lenticular and elongated bodies, ferrichromite pods, disseminations of copper, nickel, and cobalt) and can also contain traces of platinum group minerals.
\end{abstract}

Key words: Ultramafic-mafic rocks, Geologic characteristics, Metallogenetic potential, Mexico.

\section{Introducción}

Un magma es un sistema multicomponente en estado viscoplástico formado por una fase líquida representada por silicatos fundidos, varias fases sólidas formadas por cristales en suspensión o enclaves, y una fase gaseosa constituida por vapor de agua, $\mathrm{CO}_{2}, \mathrm{HCl}, \mathrm{HF}, \mathrm{SO}_{2}, \mathrm{BO}_{3}, \mathrm{H}_{2} \mathrm{~S}$, etc. A profundidad, en el manto superior, el magma asciende por diapirismo y puede interactuar con o sin mezcla parcial de la peridotita reactante (Kelemen et al., 1992). En la base de la corteza, el magma se puede comportar de forma estacionaria, constituyendo cámaras magmáticas, en las que se produce un fraccionamiento de minerales (cristalización fraccionada) o interacciones con el encajonante (asimilación magmática). Esto produce cambios importantes en su composición química, temperatura, etc. En estas cámaras magmáticas, durante su enfriamiento, comúnmente hacia su base, se forman rocas de grano grueso, pseudoestratificadas en ocasiones, llamadas acumulados magmáticos. La naturaleza y la sucesión de minerales acumulados constituidos por minerales ferromagnesianos y plagioclasas en proporciones variables, están estrechamente ligadas a la composición química del magma y a los procesos físico-químicos (diferenciación magmática, cristalización fraccionada, sedimentación de cristales, convección), que lo afectan durante su cristalización.

En el magma, además de los elementos mayores que forman los minerales esenciales de los acumulados, se encuentran elementos traza como los elementos de transición ( $\mathrm{Cr}$, Ni y Co), $\mathrm{Cu}$ y los elementos del grupo del platino (EGP=Pt, Pd, Rh, Ru, Ir y Os). La concentración y precipitación de los mismos puede determinar la formación de depósitos minerales económicos. Aunque algunos de estos elementos, como $\mathrm{Cr}$ y Ni, pueden entrar en la estructura cristalina de los silicatos, otros elementos como $\mathrm{Cu}$ y los EGP precipitan como sulfuros o en forma nativa, formando éstos últimos los minerales del grupo del platino (MGP). Los EGP también pueden precipitar en forma de arseniuros, aleaciones Os-Ir, Ir-Ru, etc. El comportamiento de estos metales depende de parámetros tales como la temperatura, la actividad de los metales y las fugacidades de oxígeno $\left(f \mathrm{O}_{2}\right)$ y azufre $\left(f \mathrm{~S}_{2}\right)$. En el manto superior la liberación de los EGP es favorecida por los altos grados de fusión parcial.

En México existen más de veinte complejos ultramáficos-máficos (UM-M) que, además de evidenciar la presencia de cámaras magmáticas, son portadores de mineralización no metálica y metálica. 
El presente trabajo consigna el análisis geológico de los principales complejos UM-M, los relaciona con su contexto tectónico y propone su potencial metalogenético.

\section{Localización y marco geológico}

Se han encontrado complejos UM-M en diez estados de la República Mexicana: Baja California, Baja California Sur, Sinaloa, Tamaulipas, Guanajuato, Guerrero, Estado de México, Puebla, Oaxaca y Chiapas (Figura 1), es decir, en las porciones noroccidental, centro, meridional-meridional oriental y nororiental del país. Estos complejos están asociados a los siguientes terrenos tectonoestratigráficos definidos por Sedlock et al. (1993): Yuma, Cochimí, Tahué, Guachichil, Tepehuano, Náhuatl, Mixteco, Cuicateco y Maya, aunque son más abundantes en los terrenos Tahué y Náhuatl. Recientemente ha sido descrita la presencia de complejos UM-M en el estado de Sonora (RodríguezCastañeda et al., 2003), relacionados con el terreno de Norteamérica.

A continuación se mencionan las características de los complejos UM-M, descritos del más antiguo al más reciente (Tabla 1).

\subsection{Complejos UM-M del Paleozoico}

Los complejos UM-M de edad paleozoica en México están representados por los afloramientos del Cañón del Novillo en Tamaulipas (terreno Guachichil), El Fuerte, Agua Caliente y Mazatlán en Sinaloa (terreno Tahué), y Tehuitzingo-Tecomatlán en Puebla (terreno Mixteco).

El terreno Guachichil del noreste de México tiene numerosas unidades tectonoestratigráficas (Sedlock et al., 1993): gneiss grenvillianos en facies de granulita que afloran en el núcleo de antiformes, rocas metasedimentarias del Paleozoico inferior a medio; metabasitas y metasedimentos del Paleozoico, y metasedimentos originados durante la subducción pérmica y depósitos de tipo Flysch. Dicho terreno incluye una cubierta sedimentaria de capas rojas del Triásico tardío-Jurásico medio y secuencias calcáreas del Jurásico Superior-Cretácico Inferior. El terreno Guachichil fue deformado durante la orogenia Laramide e intruido por granitoides durante el Cenozoico temprano (Sedlock et al., 1993).

\subsubsection{Cañón del Novillo, Tamaulipas}

En el Cañón del Novillo, que se encuentra en el núcleo del Anticlinorio de Huizachal-Peregrina, aflora un cuerpo

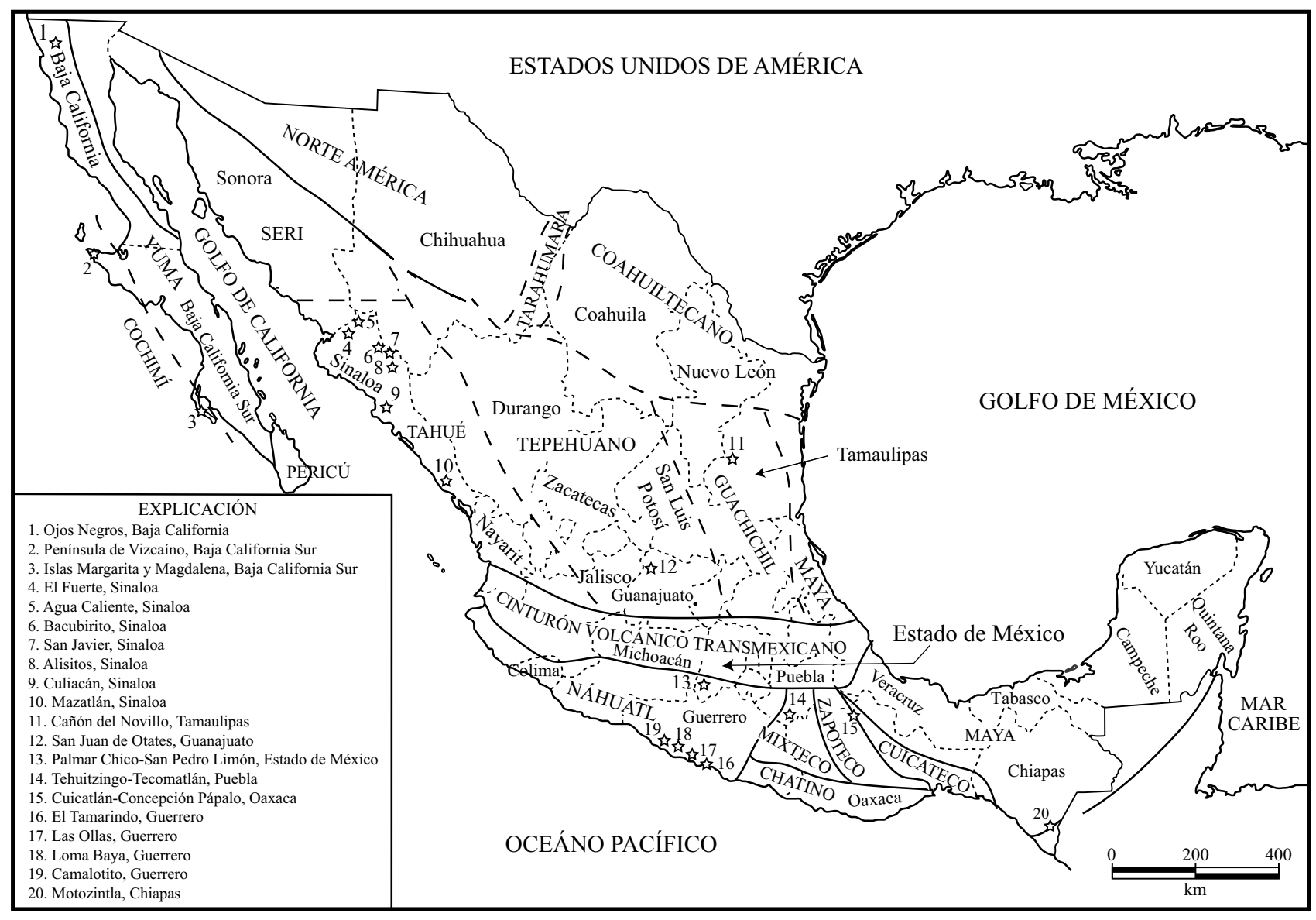

Figura 1. Localización de los complejos ultramáficos-máficos de México. Límites de los terrenos tectonoestratigráficos según Sedlock et al. (1993). 


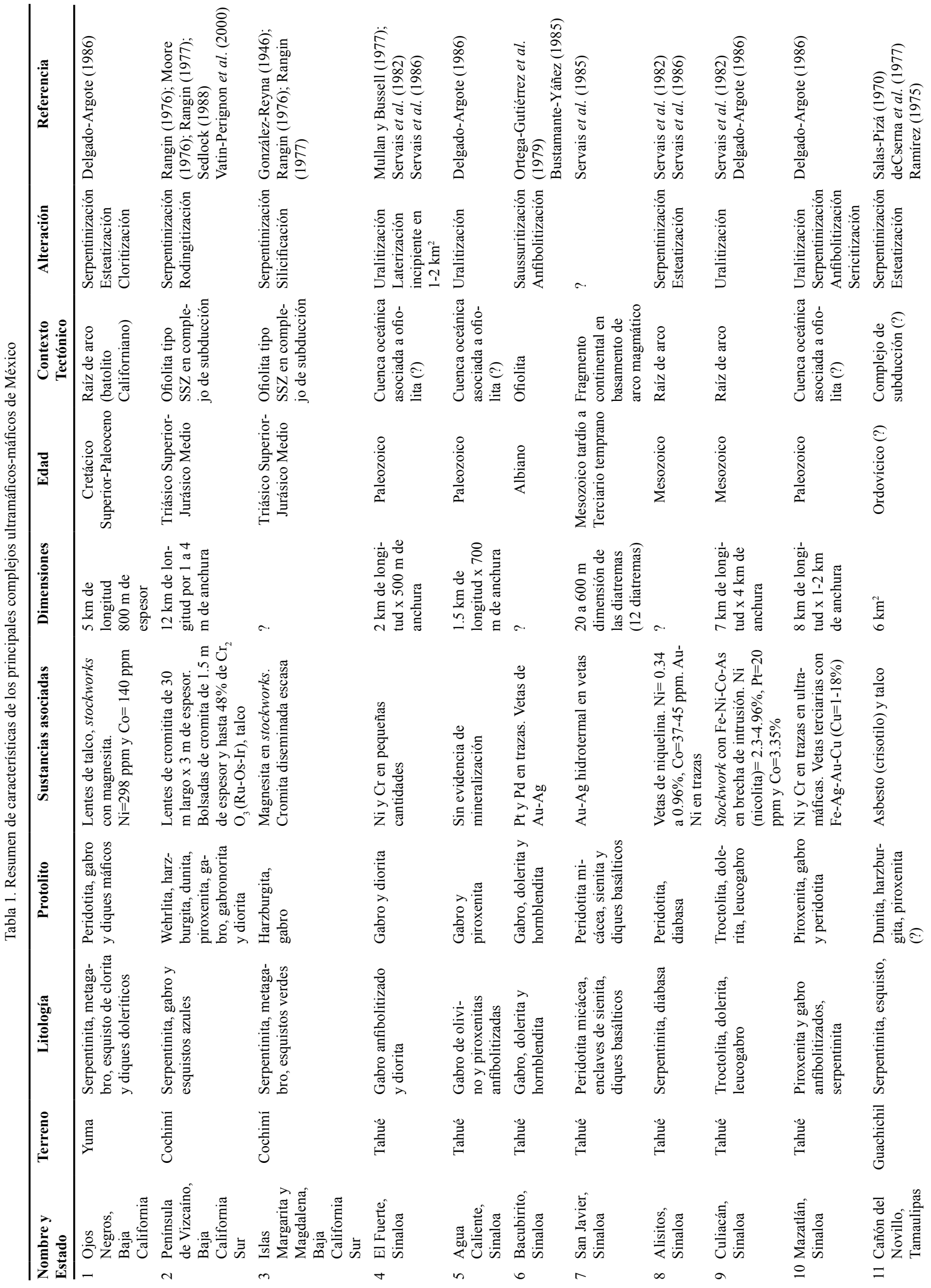


Complejos ultramáficos-máficos de México

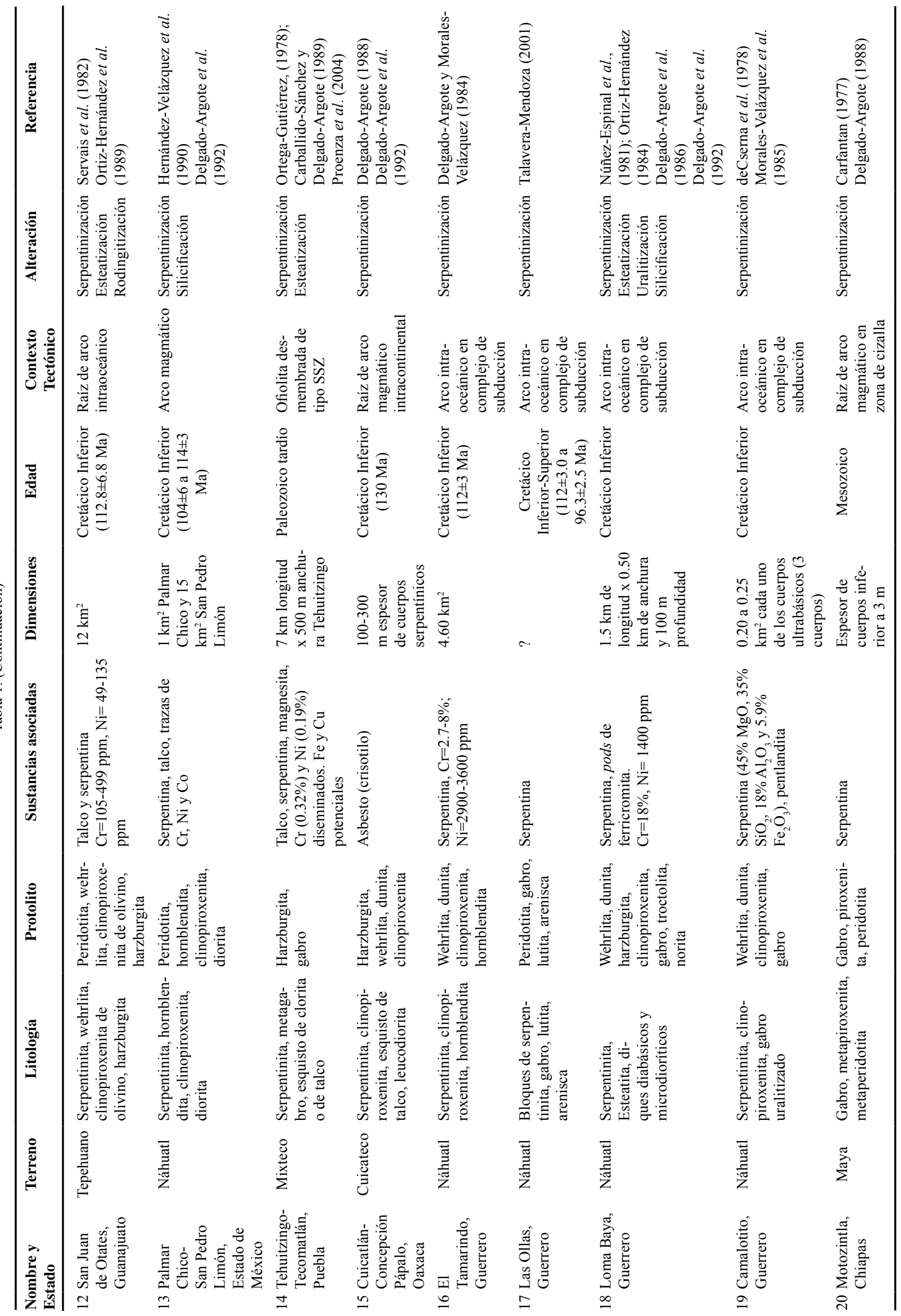


elongado orientado NNW-SSE de serpentinitas $(\sim 7 \mathrm{~km}$ de longitud por $\sim 0.85 \mathrm{~km}$ de anchura, para un área total de $\sim 6$ $\mathrm{km}^{2}$ ) subyacente al Esquisto Granjeno del Ordovícico (?), pero relacionado íntimamente con el gneiss dado que su foliación es paralela al rumbo del esquisto. Se considera como un conjunto alóctono yuxtapuesto posteriormente a la formación del Gneiss Novillo, formado por gneiss, anortositas y metagabros del Precámbrico (1140 \pm 80 a $744 \pm 25$ Ma; de Cserna et al., 1977; Sedlock et al., 1993). Aunque su origen es controvertido, el Esquisto Granjeno puede corresponder a un complejo de subducción (Sedlock et al., 1993). Según Salas-Pizá (1970) este cuerpo serpentínico representa un dique-estrato cuyo protolito fue una dunita (aunque podría haber sido una harzburgita, Travis, 1980, in Delgado-Argote, 1986). Para Ramírez (1975), existen dos protolitos de las rocas ultramáficas: unas peridotitas foliadas que dieron origen a esquistos de crisotilo y talco, $\mathrm{y}$ unas peridotitas o piroxenitas que generaron serpentinitas masivas o equigranulares con cromita y pentlandita como minerales accesorios. Las reservas calculadas por el Consejo de Recursos Minerales (2002) en un cuerpo serpentínico de $4.5 \mathrm{~km}$ longitud y $0.35 \mathrm{~km}$ anchura (Figuras 2 y 3) son del orden de $677 \mathrm{Mt}$ de serpentina y asbesto. La serpentinita tiene una composición de 29\% $\mathrm{MgO}, 4.43 \%$ $\mathrm{Fe}_{2} \mathrm{O}_{3}, 39.48 \% \mathrm{SiO}_{2}, 0.13 \% \mathrm{~K}_{2} \mathrm{O}$ y $0.16 \% \mathrm{Na}_{2} \mathrm{O}$ (Consejo de Recursos Minerales, 2002). El crisotilo tiene un potencial de $2.4 \mathrm{Mt}$ con contenidos de 5.55\%. Algunas muestras de sedimentos analizados por espectroscopía de emisión de plasma (ICP) arrojaron valores bajos de platino, del orden de 1-1.5 ppb.

\subsubsection{Complejos UM-M en Sinaloa}

Los tres complejos UM-M paleozoicos en Sinaloa (El Fuerte, Agua Caliente y Mazatlán) pertenecen al terreno Tahué que aflora en el noroeste de México y consiste de rocas pelágicas y silicoclásticas mississíppicas-pérmicas, afectadas por metamorfismo regional en facies de esquistos verdes y anfibolita (Mullan y Bussell, 1977). Las rocas del basamento de este terreno son gneisses del Paleozoico. También se encuentran rocas de arco del Cretácico, metamorfizadas en facies de esquistos verdes (Bonneau, 1972; Servais et al., 1982 y 1986). Ocasionalmente escamas ofiolíticas (?) sobreyacen tectónicamente a estas rocas.

En las cercanías de El Fuerte existen rocas metamórficas paleozoicas en facies de esquistos verdes que incluyen meta-argilitas, derrames y flujos piroclásticos meta-andesíticos, metacalizas y metapedernales mientras que hacia Mazatlán las rocas son de tipo Flysch, asociadas con metaconglomerados, metacalizas y rocas metavolcánicas, que varían de facies de esquistos verdes a anfibolita (Mullan, 1978).

El Fuerte es un complejo esencialmente máfico que aflora en la localidad de Realito y consiste en una escama de $2 \mathrm{~km}$ de longitud por $0.5 \mathrm{~km}$ de anchura. Su foliación es concordante con la de las rocas metasedimentarias, lavas y tobas encajonantes del Paleozoico (Grupo Río Fuerte).
Este cuerpo es considerado por Mullan y Bussell (1977) como un dique-estrato alojado en las rocas paleozoicas. Las rocas máficas están compuestas por acumulados de hornblenda con plagioclasas en posición intercumulus, y gabros anfibolitizados con remanentes de diópsido uralitizado. Debido al metamorfismo, se formaron también talco y clorita. Los valores en $\mathrm{Ni}$ y $\mathrm{Cr}$ de este complejo son muy bajos.

El complejo de Agua Caliente es también de composición máfica y ocurre en una superficie de $1.5 \mathrm{~km}$ de longitud por $0.7 \mathrm{~km}$ de anchura como escama tectónica. Su núcleo está formado por gabros de olivino y piroxenitas anfibolitizadas cortadas por diques doleríticos. No existen evidencias de mineralización en este complejo.

El complejo UM-M de Mazatlán consiste en un cuerpo ultramáfico-máfico de $8 \mathrm{~km}$ de longitud por 1 a $2 \mathrm{~km}$ de anchura, orientado E-W, concordante con la foliación de su encajonante (esquistos de muscovita del Paleozoico; Clark, 1973). El contacto entre ambas unidades es por falla inversa. La litología representativa de este complejo UM-M consiste en piroxenitas anfibolitizadas, gabros con anfíbol, pórfidos gabroicos, meladioritas y serpentinitas. Los valores de $\mathrm{Cr}$ y $\mathrm{Ni}$ en estas rocas son bajos, aunque existen vetas terciarias con una asociación $\mathrm{Fe}-\mathrm{Ag}-\mathrm{Au}-\mathrm{Cu}$. En éstas, los valores de $\mathrm{Cu}$ varían entre 1 y $18 \%$, siendo los minerales portadores crisocola, azurita y malaquita. La alteración característica de las rocas UM-M de Mazatlán es la uralitización, con sericitización sobreimpuesta. La litología metasedimentaria y metavolcánica que encajona a los complejos UM-M de Sinaloa, y la concordancia de la foliación de éstos con las del encajonante paleozoico, indican que se formaron en la misma secuencia volcanosedimentaria en contexto de cuenca oceánica asociada a ofiolitas (?).

\subsubsection{Tehuitzingo-Tecomatlán, Puebla}

En el sur de México, el complejo UM-M de Tehuitzingo-Tecomatlán en Puebla pertenece al terreno tectonoestratigráfico Mixteco, que está caracterizado por la presencia de basamento del Paleozoico inferior constituido por el complejo polimetamórfico Acatlán. De acuerdo con Ortega-Gutiérrez (1978) y Ortega-Gutiérrez et al. (1999), el complejo Acatlán se subdivide en los Grupos Petlalcingo y Piaxtla. El Grupo Petlalcingo incluye las formaciones Cosoltepec y Chazumba, así como también la migmatita Magdalena. Litológicamente el Grupo Petlalcingo está constituido por filitas, cuarcitas, esquistos de biotita, pelitas ricas en granate, migmatitas bandeadas y foliadas, gneiss de hornblenda y ortogneiss. El metamorfismo varía de facies de esquistos verdes a anfibolita y esporádicamente es migmatítico. El Grupo Piaxtla es una secuencia alóctona de rocas ultramáficas-máficas asociadas a sedimentos pelíticos (Formación Xayacatlán) y granitoides milonitizados que varían de ultramilonitas a augengneiss (granitoides Esperanza). Las rocas del Grupo Piaxtla están afectadas por metamorfismo en facies de eclogita (temperaturas de 


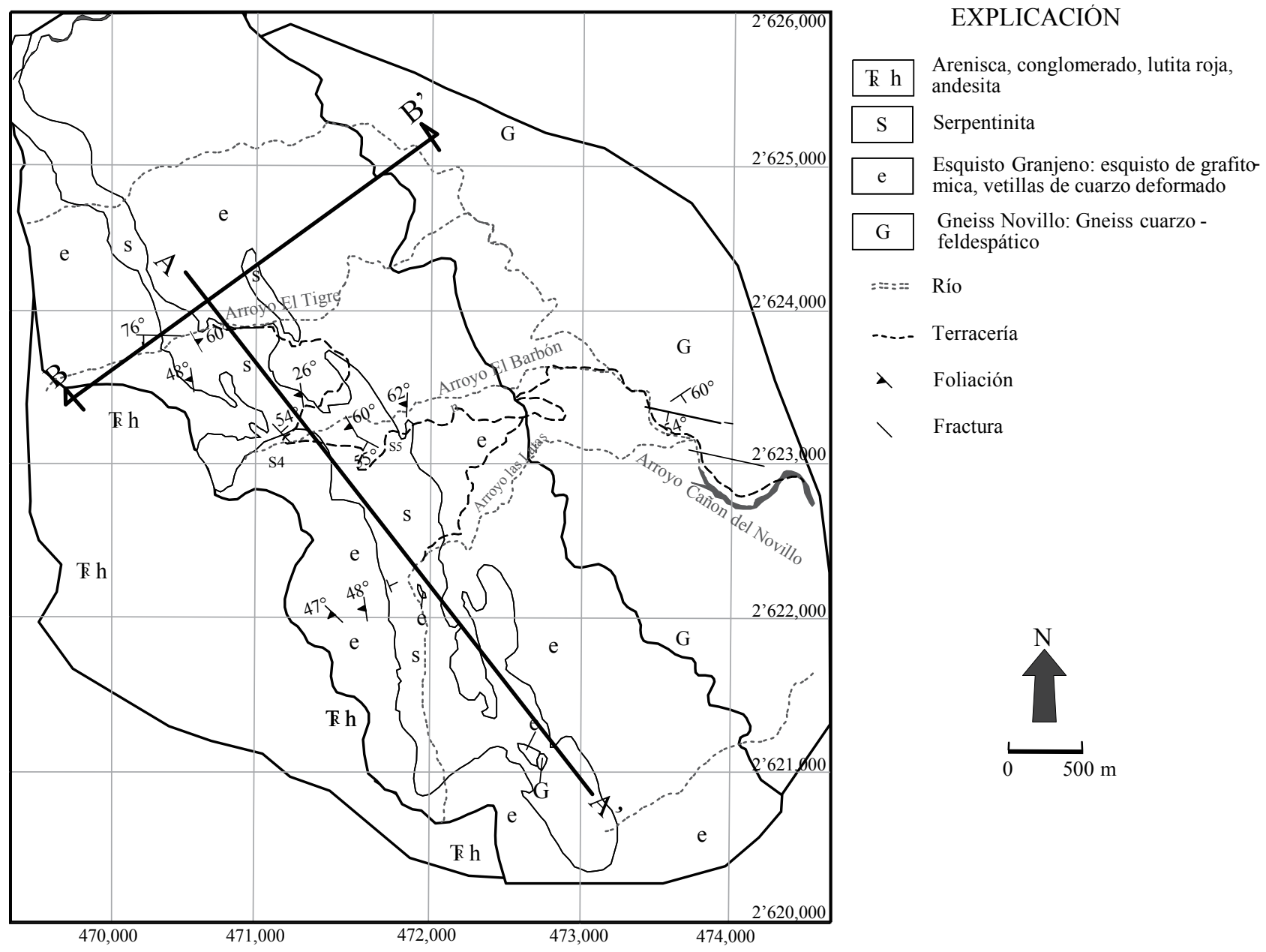

Figura 2. Mapa geológico del Cañón del Novillo, Tamaulipas. Modificado de Consejo de Recursos Minerales (2002)

A $\quad A^{\prime}$

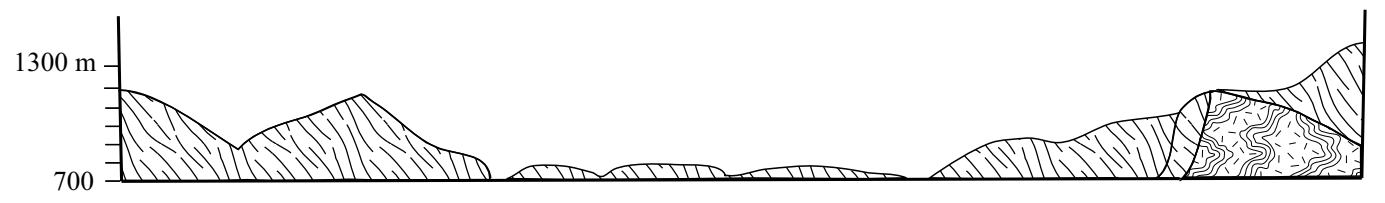

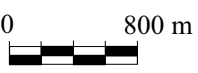

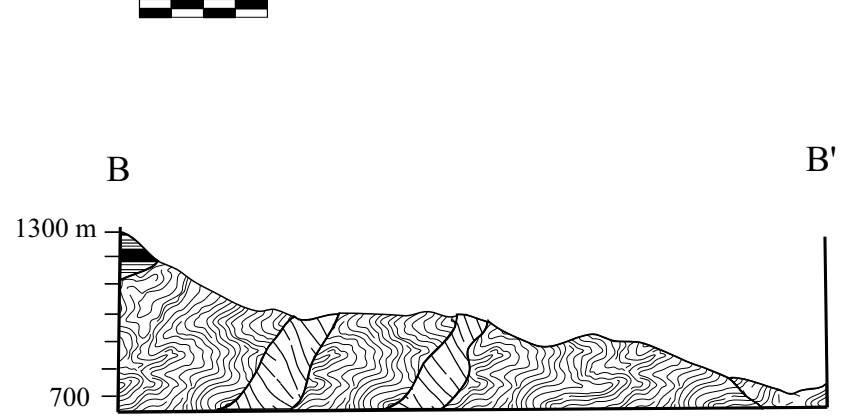

EXPLICACIÓN

Arenisca, conglomerado, lutita roja y andesita Serpentinita

Esquisto Granjeno: esquisto de grafito-mica y vetillas de cuarzo

Gneiss Novillo: Gneiss cuarzo-feldespático bandeado

Figura 3. Sección geológica del Cañón del Novillo, Tamaulipas. Modificado de Consejo de Recursos Minerales (2002) 
$560 \pm 60{ }^{\circ} \mathrm{C}$ y presiones entre 11-15 kbar; Meza-Figueroa et al., 2003). Las eclogitas han experimentado un metamorfismo retrógrado a facies de anfibolita con epidota y esquistos verdes probablemente durante el Devónico (Meza-Figueroa et al., 2003). El subgrupo Acateco es una secuencia volcanosedimentaria metamorfizada en facies de esquistos verdes cuyos protolitos son basaltos, riolitas, grauvacas, arcosas, cuarcitas, conglomerados y calizas (Formación Tecomate). El complejo Acatlán está sobreyacido por conglomerados, lutitas, limolitas y calizas de la formación Los Arcos-Olinalá (Corona-Esquivel, 1981), del Pérmico, y por rocas marinas y continentales del Jurásico-Cretácico.

La secuencia alóctona constituida por peridotitas serpentinizadas, metabasitas eclogitizadas, esquistos pelíticos y cuarcitas, es interpretada como una ofiolita desmembrada (Ortega-Gutiérrez, 1978) de tipo zona de suprasubducción SSZ (Proenza et al., 2004). En Tehuitzingo hay escamas fuertemente deformadas y metamorfizadas de serpentinita, que se han interpretado como porciones del cuerpo mayor serpentínico. Éste es una masa elongada orientada N-S de $7 \mathrm{~km}$ de longitud por $0.5 \mathrm{~km}$ de anchura cuyo protolito pueden ser harzburgitas asociadas a diques espilitizados y metagabros de augita y tremolita que, en su conjunto, fueron emplazados diapíricamente y yuxtapuestos a lo largo de una falla inversa en la Formación Tecomate (Carballido-Sánchez y Delgado-Argote, 1989). Las rocas UM son en su mayoría esquistos de antigorita-lizardita con casi un $100 \%$ de serpentinización, con esquistos de talco, esquistos de clorita y serpentinitas masivas. En estas rocas se han reconocido "pods" de magnetita y cromitita de grado refractario (rica en $\mathrm{Al}$ ) con contenidos en elementos del grupo de platino (Os, Ir, $\mathrm{Ru}$ ), variando de 102 to 33 ppb (Proenza et al., 2004), así como vetillas y diseminaciones de magnesita y calcita. La asociación de MGP está caracterizada por la presencia de laurita, ironsita y aleaciones Ru-Os (Zaccarini et al., 2005). En Tecomatlán hay diseminaciones de cromita, muscovita cromífera (fuchsita) y epidota cromífera. Este complejo no presenta potencial por níquel y sus valores en cromo son muy bajos.

\subsection{Complejos UM-M del Mesozoico}

\subsubsection{Triásico-Jurásico}

Los terrenos Yuma y Cochimí constituyen el basamento de la península de Baja California. El terreno Yuma comprende rocas de arco magmático del Jurásico y Cretácico y rocas clásticas de tipo Flysch del Triásico-Cretácico, intruidas por granitoides del Batolito Peninsular (edades de 140-80 Ma y 118-83 Ma; Ortega-Rivera, 2003). El terreno Cochimí consiste en rocas ofiolíticas y de arco, y en una zona de mélange con matriz de serpentinita.

Los complejos UM-M más antiguos del Mesozoico se encuentran en la península de Vizcaíno y la Isla de Cedros en Baja California, así como en las Islas Margarita y Magdalena en Baja California Sur, todas ellas pertenecientes al terreno Cochimí (Sedlock et al., 1993). Este terreno incluye varios subterrenos (Sedlock et al., 1993) que consisten en rocas de arco y ofiolitas (subterrenos Choyal, Vizcaíno Norte y Vizcaíno Sur) y una zona de mélange con matriz serpentínica.

El subterreno Choyal incluye a las islas de Cedros y de San Benito y consiste en un complejo ofiolítico del Jurásico medio desarrollado en un arco volcánico contemporáneo con rocas basálticas y dacíticas intruidas por diques y troncos tonalíticos-granodioríticos, conocidos como Formación Choyal. El complejo ofiolítico se interpreta como formado adyacente a un arco (Kimbrough, 1985), de acuerdo a las relaciones concordantes con las unidades volcánicas y clásticas de la Formación Choyal. Esta secuencia incluye tres unidades principales: la unidad inferior consiste en harzburgita-dunita, dunita cumulítica, wehrlita y piroxenita; la unidad intermedia consiste en gabro, diorita, plagiogranito y diques máficos; y la unidad superior está formada por rocas basálticas y andesíticas.

El subterreno Vizcaíno Norte está constituido por ofiolitas del Triásico cubiertas por rocas tobáceas y sedimentarias de la Formación San Hipólito del Triásico tardío, y por conglomerados, areniscas, lutitas y lavas almohadilladas relacionadas con la Formación Eugenia del Jurásico Superior-Cretácico Inferior. El subterreno Vizcaíno Sur consiste en ofiolitas triásicas que afloran en San Pablo y San Hipólito, y están cubiertas por pedernales, limolitas, brechas y areniscas de la Formación San Hipólito. Ambos subterrenos (Vizcaíno Norte y Sur) son fragmentos de arcos de islas, probablemente originados sobre corteza oceánica triásica. Éstos fueron acrecionados al borde continental de Norteamérica durante el Triásico tardío o el Cretácico temprano, cuando se yuxtapusieron a lo largo de una zona de falla que contiene la mélange de Sierra de los Placeres.

La ofiolita de la Sierra de San Andrés consiste en peridotitas serpentinizadas, harzburgitas, gabros cumulíticos, troctolitas, dunitas, diques de rodingita y diabasa, y plagiogranitos (Moore, 1976). La mélange de Puerto Nuevo aflora como una ventana tectónica que corta rocas ofiolíticas $\mathrm{y}$ consiste en bloques de brechas de serpentinita, esquistos verdes, esquistos azules, ortogneiss, anfibolitas y eclogitas (Sedlock, 1988).

Las rocas UM-M de la península de Vizcaíno pueden ser consideradas como una ofiolita de tipo zona de suprasubducción (SSZ ophiolite) de acuerdo a Pearce et al. (1985), aunque Radelli $(1994,1995)$ sugiere que se trata de un complejo intrusivo estratiforme debido a una acrección sub-cortical.

\subsubsection{Sierra de San Andrés e Isla de Cedros, Baja California}

La ofiolita tectonizada de la Sierra de San Andrés está constituida por peridotitas serpentinizadas, harzburgitas, 
gabros cumulíticos, troctolitas, dunitas, diques de rodingitas y diabasas, brechas, y plagiogranitos con afinidad magmática de toleítas tipo MORB (Moore, 1976). La mélange de Puerto Nuevo aflora como una ventana tectónica que corta a las rocas ofiolíticas, y consiste en bloques de brechas de serpentinita, de esquistos verdes, esquistos azules, ortogneiss, anfibolitas y eclogitas (Sedlock, 1988). La serpentinización es ubicua en las rocas ultramáficas ( $>95 \%$ de la roca), mientras que la rodingitización sugiere un metasomatismo hidrotermal cálcico. La mineralización asociada incluye lentes de cromitita y stockworks de magnesita en al menos nueve localidades (Tabla 2), siendo el prospecto El Tigre el más importante (Figura 4) con lentes de cromita de $30 \mathrm{~m}$ de longitud, por $3 \mathrm{~m}$ de espesor, y contenidos en $\mathrm{Cr}_{2} \mathrm{O}_{3}$ de hasta $48.7 \%$. Estas cromititas contienen trazas de Ru-Os-Ir (Vatin-Perignon et al., 2000). Durante el periodo 19821993 se extrajeron 13,000 toneladas de cromita, y 63,000 toneladas de magnesita entre 1981 y 1984 . El Consejo de Recursos Minerales (2000) evaluó en tres depósitos de San José la presencia de 800,000 toneladas de magnesita, con contenidos de $86.37 \%$ de $\mathrm{MgCO}_{3}$ y $2.50 \%$ de $\mathrm{CaCO}_{3}$, mientras que en la alteración Puerto Nuevo I, la Compañía Minera Tonalco S.A., calculó 102 Mt posibles de talco de baja pureza.

En la porción meridional de la Isla de Cedros (prospecto Punta Prieta-El Engaño) aparece una mineralización de cromita diseminada y en pods en serpentinitas (longitudes de 2 a $32 \mathrm{~m}$ y espesores de 0.50 a $1.50 \mathrm{~m}$ ), asociadas a gabros, microgabros, diques diabásicos, basaltos almohadillados, y una cobertura volcanosedimentaria, cabalgando a rocas metamórficas en las que se incluyen esquistos azules (Rangin, 1977). En arroyos cercanos se reconocen placeres cromíferos, pero se desconoce su potencial económico, aunque es probable que se trate de ferricromita, dado que se asocia íntimamente a manifestaciones de magnetita.

\subsubsection{Islas Margarita y Magdalena, Baja California Sur}

Las Islas Margarita y Magdalena en Baja California Sur presentan excelentes afloramientos de rocas oceánicas triásicas consideradas como un complejo ofiolítico (Rangin, 1976). En las inmediaciones de Puerto Magdalena se encuentran rocas UM serpentinizadas (harzburgitas), metagabros cumulíticos, esquistos máficos, pedernales y limolitas. En Isla Margarita, las rocas UM albergan bolsadas o estructuras irregulares de magnesita criptocristalina compacta asociada a ferricromita y asbestos, pero los depósitos son irregulares y de pequeña magnitud, con un tonelaje estimado en 319,646 toneladas de mineral con valores de $46.15 \%$ a $99.36 \%$ de $\mathrm{MgCO}_{3}$ (González-Reyna, 1946).

Según Castro-Leyva et al. (2001), la porción UM-M del complejo ofiolítico de Puerto Nuevo consiste de 1000 $\mathrm{m}$ de espesor de harzburgitas, lherzolitas y dunitas serpentinizadas en un $85-100 \%$ y están asociadas con cuerpos masivos de gabronoritas y diques de norita y gabros ricos en olivino/ortopiroxeno, con un espesor de $200 \mathrm{~m}$. Las rocas ultramáficas contienen cuerpos podiformes de cromitita de más de $10 \mathrm{~m}$ de longitud, paralelos a la foliación de la roca. Además, hay talco y magnesita en zonas de alteración hidrotermal.

\subsection{Cretácico}

Los complejos UM-M del Cretácico Inferior pertenecen principalmente al terreno Tahué, ya descrito (Bacubirito, Alisitos y Culiacán en Sinaloa); al terreno Náhuatl (complejos UM-M de Las Ollas, Camalotito, El Tamarindo y Loma Baya en Guerrero y Palmar Chico-San Pedro Limón en el Estado de México); uno de ellos al terreno Tepehuano (San Juan de Otates en Guanajuato); otro al Cuicateco (Cuicatlán-Concepción Pápalo en Oaxaca); y el último al terreno Maya (Motozintla en Chiapas). Con excepción de Bacubirito, que parece estar asociado a una secuencia ofiolítica de edad Albiense (Ortega-Gutiérrez et al., 1979) formada en una cuenca intra-arco (Servais et al., 1982, 1986) o en una cuenca oceánica (Freydier et al., 2000), los restantes complejos UM-M representan raíces de arco de islas (Carfantan, 1977; Servais et al., 1986; DelgadoArgote, 1988), intraoceánico (Ortiz-Hernández y Lapierre, 1991; Talavera-Mendoza, 1993; Talavera y Guerrero, 2000) o intracontinental de corta vida (Cuicatlán-Concepción Pápalo en Oaxaca; Delgado-Argote et al., 1992).

\subsubsection{Bacubirito, Sinaloa}

En Bacubirito aflora una secuencia volcano-plutónica asociada a rocas sedimentarias pelágicas del Albiano (Ortega-Gutiérrez et al., 1979), considerada como una ofiolita desmembrada y en posición estratigráfica invertida (unidad ofiolítica de Pueblo Viejo; Servais et al., 1986), constituida de la base a la cima por lavas basálticas almohadilladas intercaladas con radiolaritas y calizas pelágicas, un complejo de diques de dolerita, gabros isotrópicos y bandeados, troctolitas y melagabros y piroxenitas anfibolitizadas y anfibolitas. Esta unidad está sobrepuesta tectónicamente a una serie de arco insular (meta-andesitas, brechas, areniscas tobáceas y lavas basálticas almohadilladas, del complejo volcánico Borahui; Servais et al., 1986) y su cubierta sedimentaria (areniscas calcáreas, tobas silicificadas, pedernales y pelitas negras de la Formación Bacurato (Servais et al., 1986). Las lavas basálticas de Bacubirito son basaltos alcalinos de islas oceánicas (OIB), lo que las relaciona a un ambiente geotectónico de cuenca oceánica (Freydier et al., 2000).

No se tienen consignados datos referentes a mineralización de $\mathrm{Cr}$ o Ni, pero existen valores anómalos de platino y paladio (Bustamante-Yáñez, 1985), posiblemente localizados en stockworks a los que se asocian diseminaciones de pirrotita en las rocas gabroicas. También se encuentran vetas terciarias con $\mathrm{Au}-\mathrm{Ag}$ encajonadas en estas rocas. 
Tabla 2. Prospectos mineros de la región de Vizcaíno, Baja California Sur.

\begin{tabular}{|c|c|c|c|c|c|c|c|}
\hline $\begin{array}{l}\text { Nombre del } \\
\text { prospecto }\end{array}$ & $\begin{array}{c}\text { Roca } \\
\text { encajonante }\end{array}$ & $\begin{array}{c}\text { Forma y } \\
\text { dimensiones }\end{array}$ & Mineralogía & $\begin{array}{c}\text { Tipo de } \\
\text { alteración }\end{array}$ & Génesis & Potencial & Leyes (\%) \\
\hline El Tigre & Serpentinita & $\begin{array}{l}\text { Podiforme } \\
30 \mathrm{~m} \times 3 \mathrm{~m}\end{array}$ & Cromita & Serpentinización & $\begin{array}{l}\text { Diferenciación } \\
\text { magmática }\end{array}$ & Explotado & $\begin{array}{l}\text { Cromita }=48.7 \\
\text { Magnesita }=13.56\end{array}$ \\
\hline San Agustín & Serpentinita & Podiforme & Cromita & Serpentinización & $\begin{array}{l}\text { Diferenciación } \\
\text { magmática }\end{array}$ & Explotado & $\begin{array}{l}\text { Cromita }=48.2 \\
\text { Magnesita }=13.56\end{array}$ \\
\hline Vity & Serpentinita & $\begin{array}{l}\text { Podiforme } \\
\text { Diseminado }\end{array}$ & Cromita & Serpentinización & $\begin{array}{l}\text { Diferenciación } \\
\text { magmática }\end{array}$ & Explotado & $\begin{array}{l}\text { Cromita }=48.7 \\
\text { Magnesita }=13.56\end{array}$ \\
\hline $\begin{array}{l}\text { Alteración } \\
\text { Puerto } \\
\text { Nuevo (2) }\end{array}$ & $\begin{array}{l}\text { Serpentinita y } \\
\text { gabro }\end{array}$ & $\begin{array}{l}\text { Estructura tabular } \\
7.5 \mathrm{~km} \times 80 \mathrm{~m}\end{array}$ & Talco & Esteatización & Hidrotermal & Con posibilidades & Talco \\
\hline $\begin{array}{l}\text { Alteración } \\
\text { Puerto } \\
\text { Nuevo (1) }\end{array}$ & $\begin{array}{l}\text { Serpentinita y } \\
\text { arenisca }\end{array}$ & $\begin{array}{l}\text { Manto } \\
3.5 \mathrm{~km} \times 400 \mathrm{~m}\end{array}$ & $\begin{array}{l}\text { Cromita, Talco } \\
\text { Garnierita, } \\
\text { Niquelina }\end{array}$ & $\begin{array}{l}\text { Carbonatización } \\
\text { Silicificación } \\
\text { Serpentinización }\end{array}$ & $\begin{array}{l}\text { Hidrotermal } \\
\text { Diferenciación } \\
\text { magmática }\end{array}$ & $\begin{array}{l}\text { Con posibilidades } \\
86,400 \text { toneladas }\end{array}$ & $\begin{array}{l}\mathrm{Co}=0.05 \\
\mathrm{Ni}=0.8 \\
\mathrm{Cu}=13\end{array}$ \\
\hline La Palmita & $\begin{array}{l}\text { Serpentinita y } \\
\text { arenisca }\end{array}$ & $\begin{array}{l}\text { Estructuras tabula- } \\
\text { res y en vetillas }\end{array}$ & $\begin{array}{l}\text { Pirita, Malaquita, } \\
\text { Pirrotita }\end{array}$ & $\begin{array}{l}\text { Propilitización } \\
\text { Argilización } \\
\text { Sericitización }\end{array}$ & Hidrotermal & Con posibilidades & $\begin{array}{l}\mathrm{Au}=0.1 \text { a } 0.9 \mathrm{~g} / \mathrm{t} \\
\mathrm{Ag}=3 \text { a } 4 \mathrm{~g} / \mathrm{t}\end{array}$ \\
\hline $\begin{array}{l}\text { San } \\
\text { Cristóbal }\end{array}$ & $\begin{array}{l}\text { Serpentinita } \\
\text { Monzonita } \\
\text { Piroxenita }\end{array}$ & Lenticular o amorfa & $\begin{array}{l}\text { Hematita, } \\
\text { Pirita, } \\
\text { Azurita }\end{array}$ & $\begin{array}{l}\text { Propilitización } \\
\text { Silicificación }\end{array}$ & Hidrotermal & Con posibilidades & $\mathrm{Cu}=13$ \\
\hline San José & Serpentinita & Amorfa, globular & Magnesita & Carbonatación & Hidrotermal & $\begin{array}{l}\text { Parcialmente } \\
\text { explotado } \\
\text { Con reservas }\end{array}$ & $\begin{array}{l}\mathrm{MgO}=41.3 \\
\mathrm{CaCO}_{3}=1.4 \\
\mathrm{Al}_{2} \mathrm{O}_{3}=2.3\end{array}$ \\
\hline Magnesita & Serpentinita & Amorfa, globular & Magnesita & Carbonatación & Hidrotermal & $\begin{array}{l}\text { Explotado en } \\
\text { superficie }\end{array}$ & $\begin{array}{l}\mathrm{MgO}=41.3 \\
\mathrm{CaCO}_{3}=1.4 \\
\mathrm{Al}_{2} \mathrm{O}_{3}=2.3\end{array}$ \\
\hline El Datilón & $\begin{array}{l}\text { Gabro, diorita } \\
\text { de piroxeno, } \\
\text { tonalita }\end{array}$ & Vetas y diseminado & $\begin{array}{l}\text { Pirita, Calcopirita } \\
\text { Malaquita }\end{array}$ & Propilitización & Hidrotermal & Con posibilidades & $\begin{array}{l}\mathrm{Au}=4.11 \mathrm{~g} / \mathrm{t} \\
\mathrm{Cu}=1.95\end{array}$ \\
\hline Los Locos & $\begin{array}{l}\text { Gabro, } \\
\text { diorita de } \\
\text { piroxeno }\end{array}$ & $\begin{array}{l}\text { Tabular y } \\
\text { diseminado }\end{array}$ & $\begin{array}{l}\text { Limonita, } \\
\text { Calcopirita, } \\
\text { Pirita }\end{array}$ & $\begin{array}{l}\text { Propilitización } \\
\text { Argilización }\end{array}$ & Hidrotermal & Con posibilidades & $\begin{array}{l}\mathrm{Au}=1.6 \text { a } 7.4 \mathrm{~g} / \mathrm{t} \\
\mathrm{Cu}=0.001 \text { a } 0.19\end{array}$ \\
\hline El Tordillo & Gabro & Tabular & $\begin{array}{l}\text { Cuarzo, } \\
\text { Calcopirita }\end{array}$ & Silicificación & Hidrotermal & Con posibilidades & - \\
\hline
\end{tabular}

\subsubsection{Alisitos, Sinaloa}

En Alisitos se reconoce esencialmente un complejo básico representado por diabasas, basaltos y meta-andesitas en contacto tectónico con un cuerpo de serpentinitas de pequeñas dimensiones (Servais et al., 1982). Este complejo está encajonado en tobas, calizas, lavas y grauvacas correlacionables con la Formación Alisitos, del Cretácico Inferior. Una granodiorita del Cretácico tardío-Eoceno intrusiona al complejo UM-M. Se encuentra mineralización de $\mathrm{Au}-\mathrm{Ni}$ alojada en peridotita y latita con valores de Ni entre $0.34 \%$ y $0.96 \%$ y de Co entre 37 y 45 ppm, que contiene oro nativo, niquelina (NiAs), maucherita $\left(\mathrm{Ni}_{11} \mathrm{As}_{8}\right)$ y gersdorffita (NiAsS). El níquel se encuentra también en forma de millerita (NiS) o pentlandita (Bustamante-Yáñez, 1985) y violarita supergénica $\left.\left[(\mathrm{Ni}, \mathrm{Fe}) \mathrm{S}_{2}\right)\right]$. Según Servais et al. (1982), este complejo representa la raíz de un arco magmático.

\subsubsection{Culiacán, Sinaloa}

El depósito de Culiacán consiste en un cuerpo máfi- co de $4 \mathrm{~km}$ de anchura por $7 \mathrm{~km}$ de longitud, orientado NNW-SSE, formado por diques compuestos por troctolitas, doleritas, plagioclasitas, basaltos porfídicos, andesitas y leucogabros, afectados por un metamorfismo en facies de esquistos verdes. Intercaladas y en contacto tectónico con el cuerpo máfico se encuentran metacuarcitas y esquistos del Paleozoico a manera de techo colgante sobre un plutón granodiorítico del Terciario. La cobertura del cuerpo máfico consiste en metatobas, limolitas, cuarcitas, grauvacas y calizas del Cretácico (Servais et al., 1982). Mediante una determinación $\mathrm{K} / \mathrm{Ar}$ realizada en hornblenda del gabro porfídico en la mina Culiacán se obtuvo una edad de $51.7 \pm 1.2 \mathrm{Ma}$, que no se considera representativa de la edad de emplazamiento de este cuerpo máfico, sino la edad de un recalentamiento producido por la granodiorita adyacente (Cerecero-Luna et al., 1984). Aunque no se reconocen rocas ultramáficas, se reporta una mineralización hidrotermal de sulfuros con una asociación Fe-Ni-Co-As en una brecha de intrusión, con predominio de niquelina alterada a garnierita, acompañada de gersdorffita, arsenopirita y minerales 


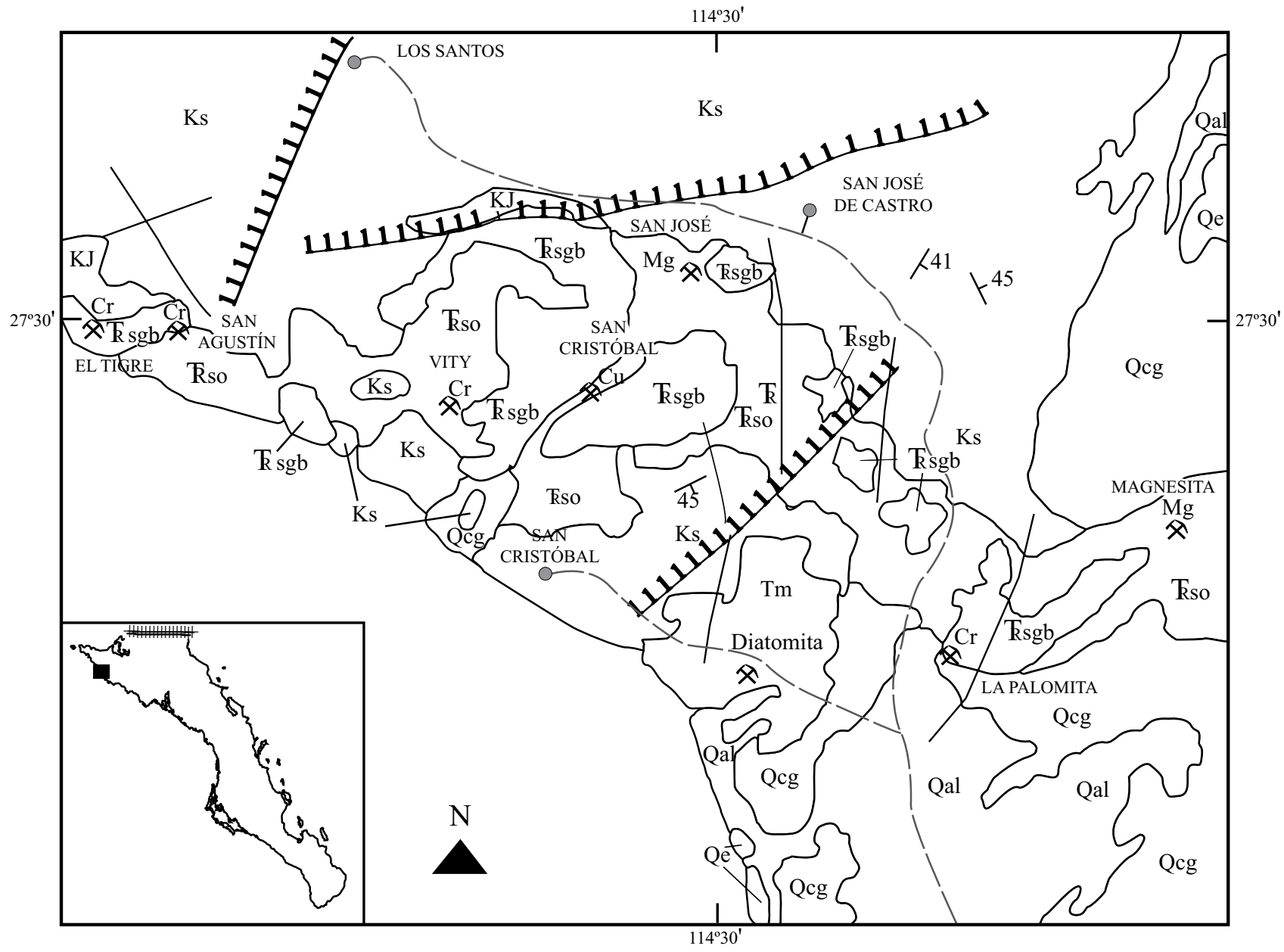

EXPLICACIÓN

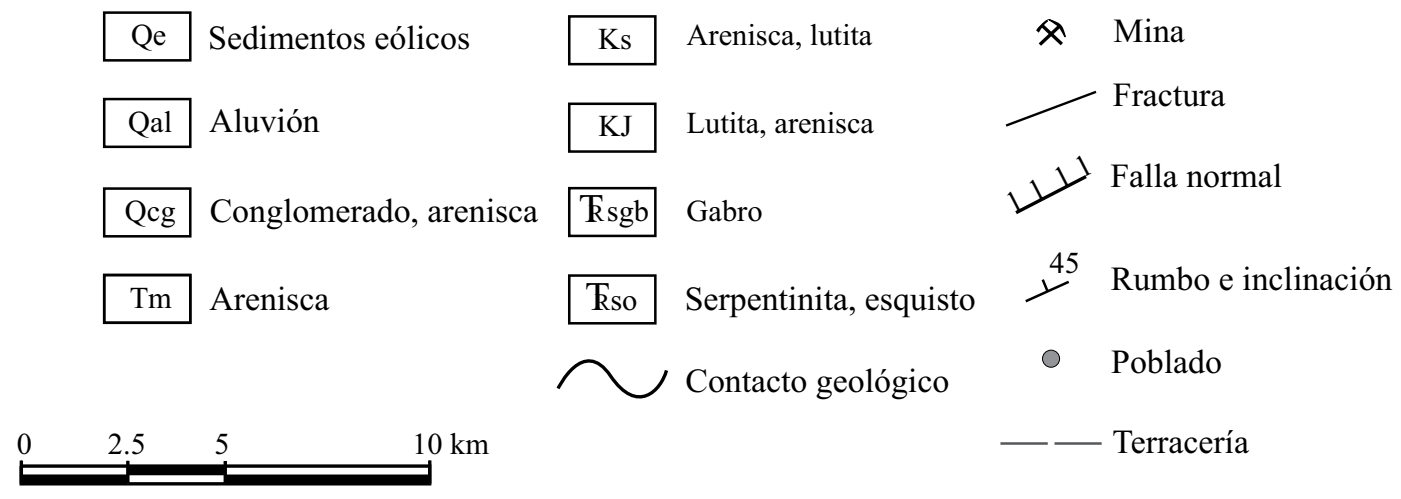

Figura 4. Mapa geológico y prospectos mineros de la Península de Vizcaíno (según Consejo de Recursos Minerales, 2000).

de cobalto como skutterudita $(\mathrm{CoNiFe}) \mathrm{As}_{3}$, escorodita $\left(\mathrm{Fe}^{3+} \mathrm{AsO}_{4} 2 \mathrm{H}_{2} \mathrm{O}\right)$, glaucodoto $(\mathrm{CoFe}) \mathrm{AsS}$, e ilmenita con trazas de $\mathrm{Ni}$, Pt e Ir. Las concentraciones de Ni varían entre $2.3 \%$ y $4.96 \%$, y los valores promedio de Pt son de $20 \mathrm{ppm}$. Las reservas potenciales por Co son del orden de 200,000 toneladas con leyes de $0.4 \%$ a $1 \%$ de Co, y además $2 \mathrm{~g} / \mathrm{t}$ de $\mathrm{Au}, 0.5 \%$ de Ni y más del $10 \%$ de As (Cerecero-Luna et al., 1984). Servais et al. (1982) interpretan también este complejo como la raíz de un arco magmático.

\subsection{Complejos UM-M de Guerrero}

El terreno Náhuatl aflora extensivamente en el sur de México y consiste de secuencias volcanosedimentarias del Jurásico Superior-Cretácico Inferior afectadas por metamorfismo regional (facies de prehnita-pumpellyita y esquistos verdes; Talavera y Guerrero, 2000; Elías-Herrera et al., 2000) y anfibolitas. Las rocas del basamento del terreno Náhuatl son augengneiss del Paleozoico tardío, y 
basaltos y rocas sedimentarias del Triásico tardío, así como esquistos de edad desconocida. La cubierta sedimentaria incluye rocas volcánicas y sedimentarias probablemente deformadas durante el Jurásico o el Cretácico (?), calizas del Cretácico Inferior, y conglomerados del Cretácico Inferior-Cretácico Superior, así como rocas volcánicas continentales del Terciario.

En el sur de México, los complejos UM-M de la costa de Guerrero incluyen Las Ollas, Camalotito, El Tamarindo y Loma Baya expuestos en la región de Papanoa-Petatlán (Figura 5). Estos complejos fueron estudiados en la década de 1980 por el Consejo de Recursos Minerales (Núñez-Espinal, 1981) y se relacionan con el subterreno Zihuatanejo-Huetamo, que representa un sistema de arco de islas evolucionado-cuenca marginal-complejo de subducción del Jurásico Superior (?)-Cretácico Inferior (Talavera y Guerrero, 2000).

Estos complejos UM-M se presentan como cuerpos elongados de serpentinita emplazados como diapiros en secuencias volcanosedimentarias (Delgado-Argote et al., 1986), o bloques exóticos de serpentinitas, gabros, lutitas y areniscas, que habían sido considerados como ofiolitas desmembradas (Núñez-Espinal et al., 1981), raíces de arco magmático (Delgado-Argote y Morales-Velázquez, 1984; Delgado-Argote et al., 1986), y más recientemente, como un complejo de subducción (Talavera y Guerrero, 2000).

\subsubsection{Las Ollas, Guerrero}

Las Ollas está constituido por escamas y bloques de rocas UM-M, calizas, cuarcitas, pedernales, tobas, lavas almohadilladas y anfibolitas incluidos en una matriz de tipo Flysch. Presenta metamorfismo de alta presión (facies de esquistos azules). Los bloques de gabros, gabros doleríticos, anfibolitas y basaltos presentan afinidad magmática de toleítas de arco inmaduras (Talavera y Guerrero, 2000). Determinaciones geocronométricas ${ }^{40} \mathrm{Ar} /{ }^{39} \mathrm{Ar}$ en anfíbol de diques gabroicos que intrusionan al complejo de Las Ollas indican edades de $112 \pm 3.0 \mathrm{Ma}$ a $96.3 \pm 2.5 \mathrm{Ma}$ (Delgado-Argote et al., 1992; Talavera-Mendoza, 2001). Actualmente no se tiene información acerca de su potencial metalogenético.

\subsubsection{Camalotito, Guerrero.}

El complejo UM-M de Camalotito se encuentra en escamas tectónicas y está caracterizado por la presencia de serpentinitas de antigorita derivadas de protolitos wehrlíticos, duníticos y clinopiroxeníticos, relacionados con gabros uralitizados, que forman cuerpos elongados orientados NW-SE. Estas escamas están asociadas con metatobas andesíticas, filitas carbonosas, grauvacas arcósicas y lavas básicas (Figura 6) afectadas por metamorfismo regional en facies de esquistos verdes. La alteración y el metamorfismo han desarrollado una serpentinización del $60-95 \%$ de la roca con $42.5 \%$ a $47 \%$ de $\mathrm{MgO}$ y $32.7 \%$ a $38.5 \%$ de $\mathrm{SiO}_{2}$ en los dos cuerpos principales. También existe escasa diseminación de cromita y pentlandita reemplazada por bravoita $\left.\left[(\mathrm{Fe}, \mathrm{Ni}) \mathrm{S}_{2}\right)\right]$ y violarita (Morales-Velázquez et al., 1985).

\subsubsection{El Tamarindo, Guerrero}

El Tamarindo consiste de cuerpos elongados orientados $\mathrm{N}-\mathrm{S}$ de wehrlitas, dunitas, clinopiroxenitas de olivino y hornblenditas, circundados por gabros y dioritas, todo ello cortado por diques tardíos de anfibolitas. Este complejo está encajonado en rocas metavolcánicas y metasedimentarias de arco metamorfizadas en facies de los esquistos verdes (Delgado-Argote y Morales-Velázquez, 1984). Fallas transcurrentes con dirección N-S son las estructuras características que afectan a este complejo, aunque también hay fallas inversas debidas al emplazamiento del mismo y fallas normales tardías. Su brechamiento característico, fluidez y tendencia estructural sugieren que su emplazamiento fue de tipo diapírico por intrusión forzada. Los contenidos de Cr son de 2.7 a $8 \%$, los de $\mathrm{Al}_{2} \mathrm{O}_{3}$ son de $16 \%$, los de Fe son de 7\%, y los de Ni son de 2900 a 3600 ppm. Este depósito contiene diseminaciones de ferricromita, y no se descarta la posibilidad de encontrar valores de Os-Ir-Ru en los óxidos primarios y/o secundarios.

\subsubsection{Loma Baya, Guerrero}

El depósito de Loma Baya consiste en un cuerpo elongado de serpentinita de antigorita, de $1.5 \mathrm{~km}$ de longitud por $0.5 \mathrm{~km}$ de anchura, formado por wehrlitas, dunitas, harzburgitas, clinopiroxenitas, pegmatitas de hornblenda, noritas y esteatitas, en contacto tectónico con gabro de augita, troctolita, diques diabásicos y microdioríticos (Figura 6). Este cuerpo está encajonado por diorita y ocurre a manera de techo colgante en el batolito granítico de Guerrero (Núñez-Espinal et al., 1981). Según Delgado-Argote et al. (1986), este complejo UM-M fue emplazado como una intrusión forzada, y está afectado por fallas normales y transcurrentes (Núñez-Espinal et al., 1981). La mineralización que alberga corresponde a pods de ferricromita orientados según la foliación de la peridotita y contiene diseminaciones del mismo mineral. Escasa pentlandita está incluida en magnetita secundaria, que a su vez está incluida en stockworks de antigorita (Ortiz-Hernández, 1984). Sus contenidos en $\mathrm{Cr}$ son de $18 \%$, con $14 \%$ de $\mathrm{Al}_{2} \mathrm{O}_{3}, 9 \%$ de Fe y 1400 ppm de Ni. Se reconocen también valores de plata asociada a zonas de silicificación, uralitización y saussuritización tardías.

\subsubsection{Palmar Chico-San Pedro Limón, Estado de México}

En el centro de México, el complejo UM-M de Palmar Chico-San Pedro Limón consiste en acumulados ultramáficos-máficos del Albiano (edad integrada ${ }^{40} \mathrm{Ar} /{ }^{39} \mathrm{Ar}$ de 105 Ma; Delgado-Argote et al., 1992), pequeñas cuñas tectónicas de serpentinitas (wehrlitas, dunitas, hornblenditas y clinopiroxenitas de hornblenda, en un área de $1 \mathrm{~km}^{2}$ en Palmar Chico a $15 \mathrm{~km}^{2}$ en San Pedro Limón). El depósito también contiene diques diabásicos y microgabroicos (edad de 108 Ma mediante K/Ar en anfíbol; Ortiz-Hernández y 


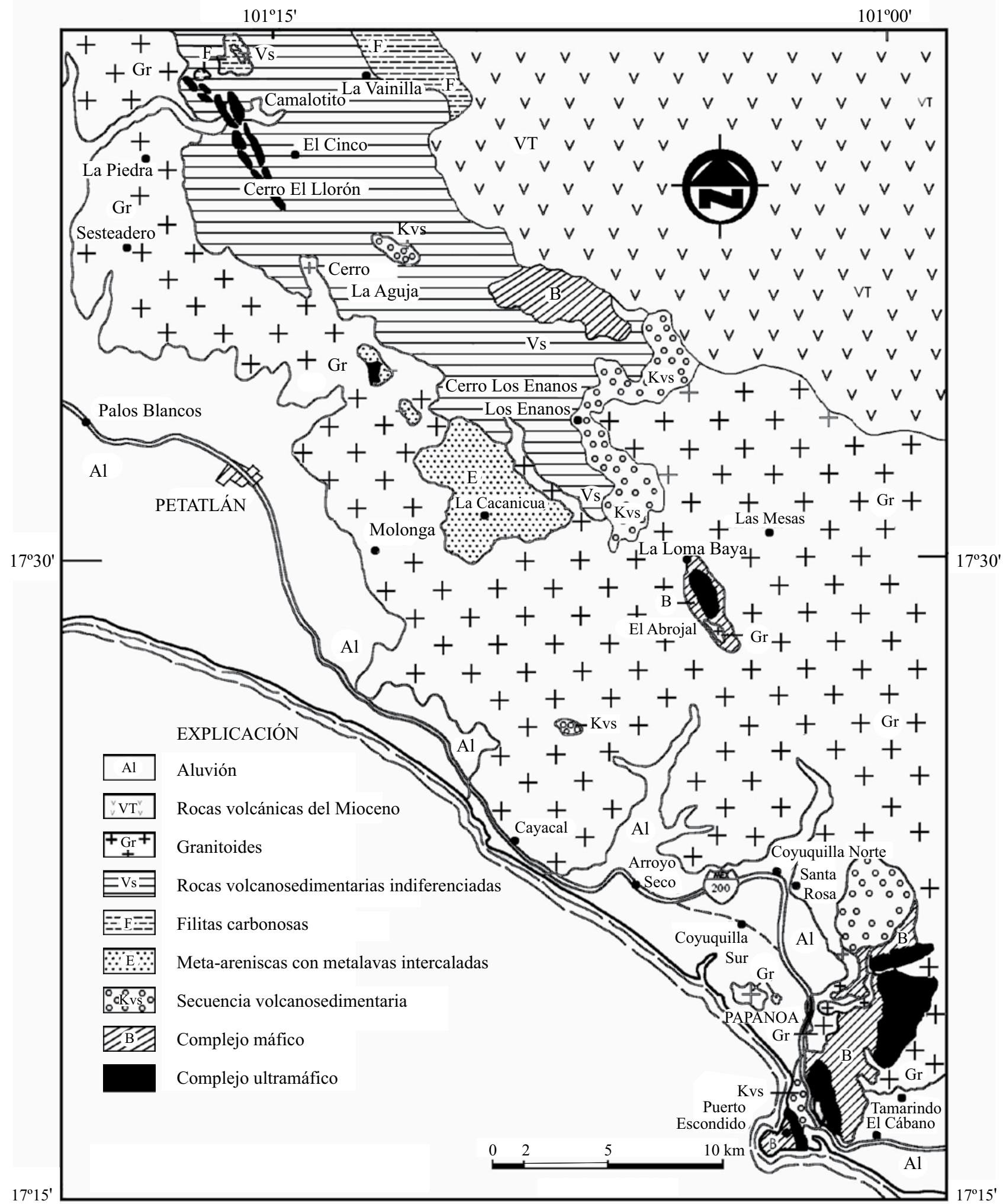

Figura 5. Mapa geológico regional de los complejos ultramáficos-máficos del estado de Guerrero (según Delgado-Argote y Morales-Velázquez, 1984; modificado por Morales-Velázquez et al., 1985). 
Lapierre, 1991), relacionados con lavas almohadilladas basáltico-andesíticas (edades de 103.1 $\pm 1.3 \mathrm{Ma}$ a 93.6 \pm 0.6 Ma mediante ${ }^{40} \mathrm{Ar} /{ }^{39} \mathrm{Ar}$, Elías-Herrera et al., 2000), brechas, hialoclastitas, y sedimentos silíceos y tufitas del Cenomaniano. Esta secuencia cabalga a la Formación Xochipala (Cenomaniano-Turoniano) y está afectada por un régimen transpresivo y un metamorfismo regional de facies prehnita-pumpellyita. La afinidad magmática de las lavas basálticas de Palmar Chico es toleítica de arco y las andesitas basálticas son calcialcalinas (Ortiz-Hernández y Lapierre, 1991), aunque también se encuentran basaltos de islas oceánicas (OIB; Talavera y Guerrero, 2000). En las cuñas tectónicas se presentan indicios de $\mathrm{Cr}$, Ni y Co (Hernández-Velázquez et al., 1990).

A

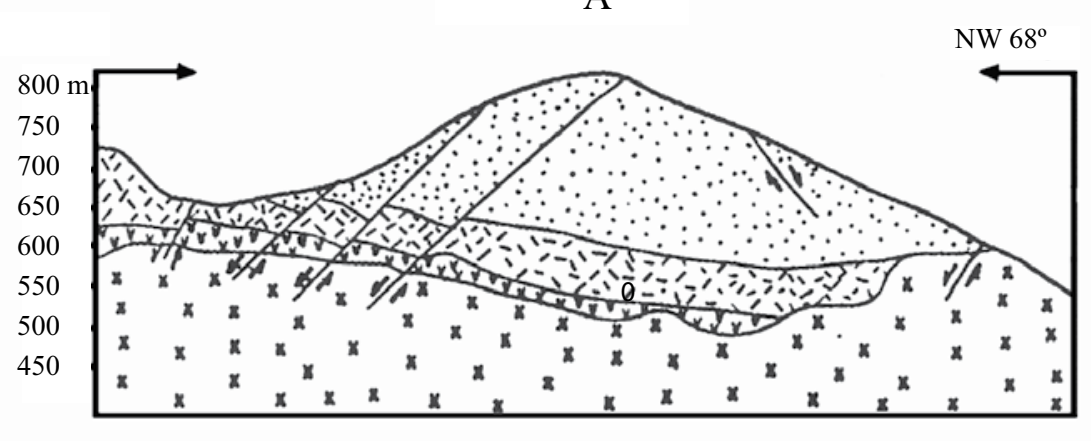

\section{EXPLICACIÓN}

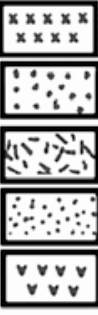

Granito Peridotitas foliadas Complejo máfico Dique microdiorítico Diabasa

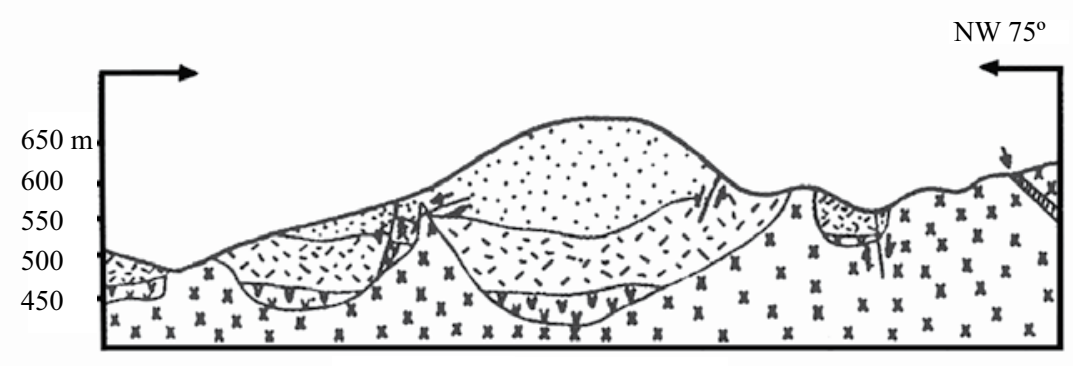

Escala 1.10,000

B

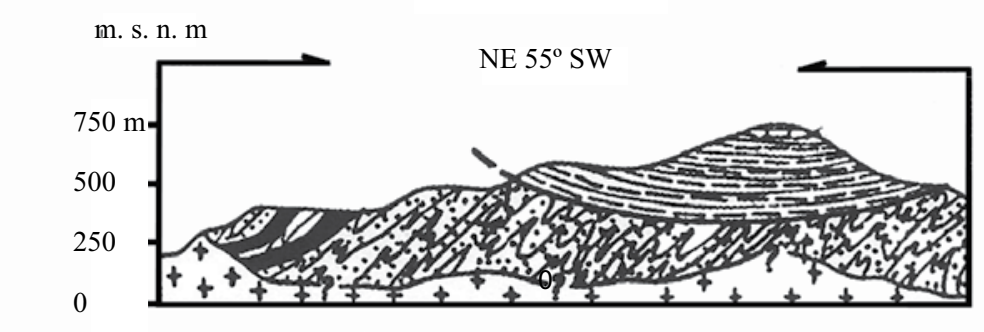

EXPLICACIÓN

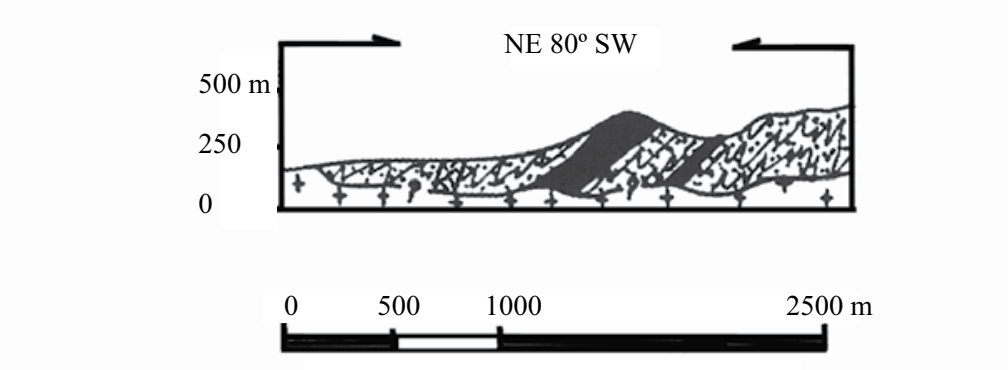

Calizas

Vilis Fitas

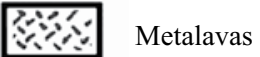

Metatobas

Figura 6. Secciones geológicas de los complejos ultramáficos-máficos de: (A) Loma Baya y (B) Camalotito, estado de Guerrero. 


\subsubsection{San Juan de Otates, Guanajuato}

En el centro del país, y expuesto gracias a los grabens que afectan el basamento mesozoico de la Sierra de Guanajuato, se encuentra el complejo UM-M de San Juan de Otates, relacionado al terreno Tepehuano.

El terreno Tepehuano incluye la provincia de la Mesa Central o Altiplano de México, y consiste al menos de cinco unidades tectonoestratigráficas (Sedlock et al., 1993): (1) el basamento cristalino proterozoico; (2) un arco jurásico continental del Triásico tardío al Jurásico temprano y rocas asociadas a una cuenca pre-arco; (3) una cubierta sedimentaria del Jurásico Superior-Cretácico medio afectada por la orogenia Laramide; (4) rocas plutónicas del Paleoceno; y (5) rocas sedimentarias y volcánicas del Neógeno depositadas durante la extensión de Cuencas y Sierras.

La Sierra de Guanajuato incluye una sección completa de un arco intraoceánico alóctono (Ortiz-Hernández et al., 1989; Lapierre et al., 1992), formado por un complejo volcano-plutónico del Cretácico Inferior constituido por lavas almohadilladas, sedimentos pelágicos, un complejo de diques de doleritas y ankaramitas, dioritas, tonalitas, gabros cumulíticos, wehrlitas, clinopiroxenitas, rodingitas y brechas magmáticas. Estas rocas se encuentran en contacto tectónico cabalgando hacia el NNE a un paraautóctono representado por una secuencia Flyschoide (Formación Arperos; Figura 7), sedimentos pelágicos calcáreo-arcillosos y lavas basálticas almohadilladas de tipo OIB, extravasadas en una cuenca oceánica. Este complejo UM-M aflora en una superficie de $12 \mathrm{~km}^{2}$. Mediante determinaciones geocronométricas $\mathrm{K} / \mathrm{Ar}$ realizadas en un gabro se obtuvo una edad de $112.8 \pm 6.8 \mathrm{Ma}$, y para una clinopiroxenita de plagioclasa de $113 \pm 7 \mathrm{Ma}$ (Lapierre et $a l .$, 1992). Eventualmente se explotó talco en pequeñas cantidades en zonas de alteración talco-carbonática de este complejo, aunque de manera irregular. Los contenidos de cromo en este depósito varían entre 105 y 499 ppm y los de níquel entre 49 y 135 ppm, pero se desconoce su potencial por EGP.

\subsubsection{Cuicatlán-Concepción Pápalo, Oaxaca}

En el sur de México, se encuentra el complejo UM-M de Cuicatlán-Concepción Pápalo perteneciente al terreno Cuicateco. Este complejo fue relacionado a lentes ofiolíticos formados en la Cuenca Cuicateca (Carfantan, 1984).

El terreno Cuicateco incluye corteza oceánica y rocas de arco del Jurásico Superior-Cretácico Inferior (DelgadoArgote, 1989), que sobreyacen estructuralmente al terreno Maya. Este terreno consiste en metatobas, metalavas, pizarras negras y metacalizas en facies de esquistos verdes que fueron depositadas en una cuenca. Estas rocas están yuxtapuestas por falla a un Flysch del Cretácico Inferior y a tobas que son probablemente remanentes del arco Chontal (Carfantan, 1984).

El asbesto explotado en Cuicatlán-Concepción Pápalo es de la variedad crisotilo (Ramírez, 1988) y se encuentra alojado en mantos de serpentinita de 100-300 m de espesor, cuyo protolito corresponde a harzburgitas y en menor proporción wehrlitas y dunitas (Delgado-Argote, 1988; Delgado-Argote et al., 1992), asociados a esquistos de talco y leucodioritas, concordantes con la foliación del encajonante. El complejo está incluido en rocas volcanosedimentarias (meta-lavas andesíticas, filonitas, meta-riolitas, meta-areniscas y meta-lodolitas) mesozoicas afectadas por metamorfismo en facies de esquistos verdes (DelgadoArgote, 1988; Delgado-Argote et al., 1992). Los mantos de serpentinita se asocian a minerales tales como tremolita y garnierita. Mediante determinaciones geocronométricas de ${ }^{40} \mathrm{Ar} /{ }^{39} \mathrm{Ar}$ realizadas por Delgado-Argote et al. (1992) en hornblendas de Teotitlán, se obtuvo una edad de 130 Ma para el depósito. Este complejo UM-M representa la raíz de un arco volcánico andesítico o un arco magmático continental de corta vida (Delgado-Argote, 1988; DelgadoArgote et al., 1992).

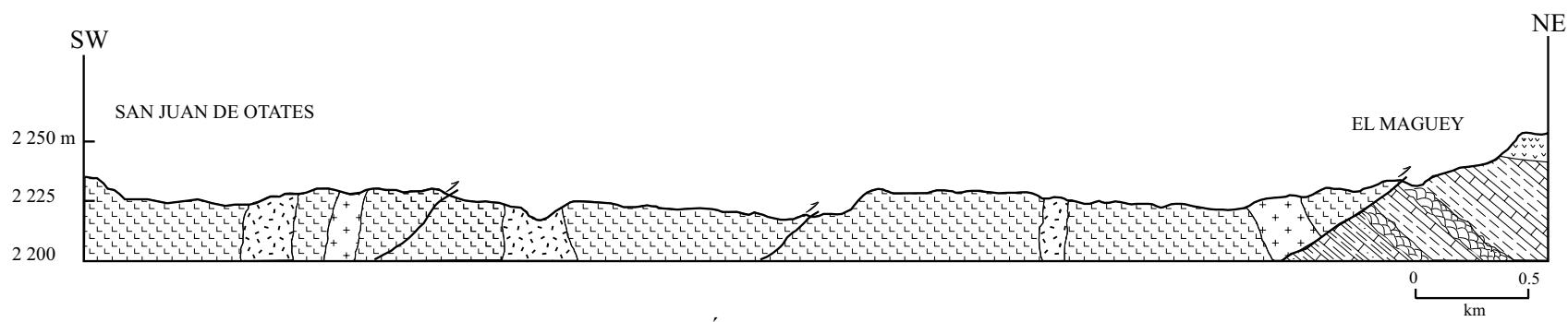

EXPLICACIÓN

$\begin{array}{lll}\text { Ignimbritas terciarias } & \text { Gabros cumulíticos } \\ & & \\ & & \\ & & \end{array}$

Figura 7. Seccion geológica del complejo ultramáfico-máfico de San Juan de Otates, Guanajuato. 


\subsubsection{Motozintla, Chiapas}

El complejo UM-M de Motozintla se ubica en el terreno Maya. El terreno Maya aflora en el este y sureste de México. $\mathrm{Su}$ basamento consiste en gneisses precámbricos $(720 \pm 10$ a 606 $\pm 30 \mathrm{Ma}$; Rincón-Orta y Damon in Salas, 1975), afectados por metamorfismo en facies de granulita, junto con rocas metavolcánicas, cuarcitas y esquistos en facies de anfibolita (Pantoja-Alor et al., 1974). Dicho basamento ha sido considerado como parte de la corteza continental de Gondwana. El batolito de Chiapas y el batolito del Soconusco consisten en granitoides de arco continental que varían en edad del Paleozoico al Cenozoico (Consejo de Recursos Minerales, 1999).

El complejo UM-M de Motozintla forma parte de un complejo volcano-plutónico alóctono formado por escamas de $3 \mathrm{~m}$ de espesor de peridotitas, piroxenitas y gabros incluidos tectónicamente en meta-andesitas, meta-tobas y meta-riolitas, afectadas por metamorfismo de facies esquistos verdes, y asociadas a granitoides y diques anortosíticos (Carfantan, 1977), que descansa tectónicamente sobre sedimentos mesozoicos. El ambiente geotectónico de formación de estos depósitos corresponde a un arco magmático emplazado durante el Cenomaniano sobre la plataforma de Chiapas (Carfantan, 1977), y actualmente se sitúa en la traza de la falla de desplazamiento lateral Polochic. Dadas sus reducidas dimensiones, no presenta potencial económico por $\mathrm{Cr}, \mathrm{Ni}, \mathrm{Co}$ ni EGP.

\subsection{Complejos UM-M del Cretácico Superior-Terciario}

Los complejos UM-M más recientes, de edad Cretácico Superior-Paleoceno están localizados en el noroccidente de México. Éstos son los de Ojos Negros en Baja California y las peridotitas de flogopita con afinidad kimberlítica de San Javier, en Sinaloa.

\subsubsection{Ojos Negros, Baja California}

Los cuerpos UM-M de Ojos Negros pertenecen al terreno Yuma, ya descrito. Afloran en dos cerros elongados orientados E-W incluidos en la porción meridional del batolito Californiano (Cretácico Superior-Paleoceno), con una longitud aproximada de $5 \mathrm{~km}$ y con un espesor de 800 $\mathrm{m}$. En este depósito se reconocen metagabros, con lineación E-W, diques doleríticos, granófiros y lentes ricos en talco y serpentina (80-90\% de serpentinización), y esquisto de clorita con stockworks de magnesita y escasos metagabros. $\mathrm{Su}$ emplazamiento puede ser intrusivo, concomitante al del batolito Californiano. Su contenido en Ni es de 298 ppm y $\mathrm{Cr}$ de 140 ppm, y ha sido explotado por talco de mala calidad.

\subsubsection{San Javier, Sinaloa}

San Javier, perteneciente al terreno Tahué ya descrito, es la única localidad de la República Mexicana donde se ha señalado la presencia de una docena de diatremas de 20 a $600 \mathrm{~m}$ de potencia, de peridotitas de flogopita de posible afinidad kimberlítica (Figura 8). Estas se encuentran asociadas a enclaves de sienita, rocas sedimentarias, y diques de basálticos microlíticos. Su encajonante son pizarras negras con escasas intercalaciones de calizas, conglomerados polimícticos y cuarcitas del Mesozoico tardío, metamorfizadas en facies de esquistos verdes (Servais et al., 1985). Estas rocas UM atestiguan la presencia de corteza continental o un fragmento continental subyacente de las series de arco mesozoicas pacíficas. Sin embargo, se encuentran lamprófidos ultramáficos (LUM tipo aillikita) que pueden presentar características similares a las de las kimberlitas (LKI; Rock, 1991). Los LUM tienen piroxenos con mayor contenido en $\mathrm{Al}_{2} \mathrm{O}_{3}$ y $\mathrm{TiO}_{2}$, flogopitas con mayor contenido en $\mathrm{TiO}_{2}$, y una menor relación $(\mathrm{La} / \mathrm{Yb})_{\mathrm{N}}$ con respecto a los LKI (Rock, 1991), como parece ser el caso de las peridotitas micáceas de San Javier. Sin embargo, en un diagrama de discriminación LUM-LKI (no mostrado), usando las relaciones $\mathrm{MgO} / \mathrm{CaO}$ vs. $\mathrm{SiO}_{2} / \mathrm{Al}_{2} \mathrm{O}_{3}$, estas rocas caen en el campo de LKI. En caso de ser realmente kimberlitas, ello evidencía un magma madre de tipo lherzolita carbonatada de flogopita, formado a presiones comprendidas entre $40 \mathrm{y}$ $50 \mathrm{~kb}$. De acuerdo con los datos mineralógicos reportados por Servais et al. (1985), y utilizando la espinela como un geotermómetro (Berger et al., 1982), se calcularon temperaturas de cristalización de este mineral entre 1137 y $1172^{\circ}$ C. En una muestra de esta roca se obtuvieron contenidos de 2 ppb Au, 10 ppb Pt, 10 ppb Pd, 10 ppb Rh, 2 ppb Ir, 1,000 ppm Ni y 63 ppm Co (Cerecero-Luna et al., 1984).

\subsubsection{Tipos de complejos UM-M en México}

Las litologías características en los complejos UM-M del Paleozoico son serpentinitas, harzburgitas, gabros, dioritas, piroxenitas y esquistos de clorita o talco. Éstos se presentan por lo común concordantes con la foliación del encajonante, lo que indicaría que son penecontemporáneos a los mismos y que fueron emplazados como dique-estratos. Estos complejos están fuertemente deformados y fracturados. La naturaleza de las litologías en que están encajonados sugiere que posiblemente se formaron en una cuenca oceánica (El Fuerte, Agua Caliente, Mazatlán), en un complejo de subducción (Cañón del Novillo), o en una ofiolita de tipo SSZ actualmente desmembrada (Tehuitzingo-Tecomatlán). Las alteraciones predominantes son serpentinización, esteatización y anfibolitización. Los complejos UM-M paleozoicos contienen valores muy bajos de $\mathrm{Ni}$ y $\mathrm{Cr}$, con escasa cromita y pentlandita y con algo de talco, crisotilo y magnesita. Fueron derivados posiblemente de magmas toleíticos ricos en olivino (tipo MORB), por lo cual su potencial metalogenético por minerales metálicos (Cr, Ni, Co, EGP) se considera escaso. Entre los complejos paleozoicos, sólo Cañón del Novillo y Mazatlán pueden tener potencial económico por asbesto y $\mathrm{Cu} \pm \mathrm{Ag} \pm \mathrm{Au}$, respectivamente. 


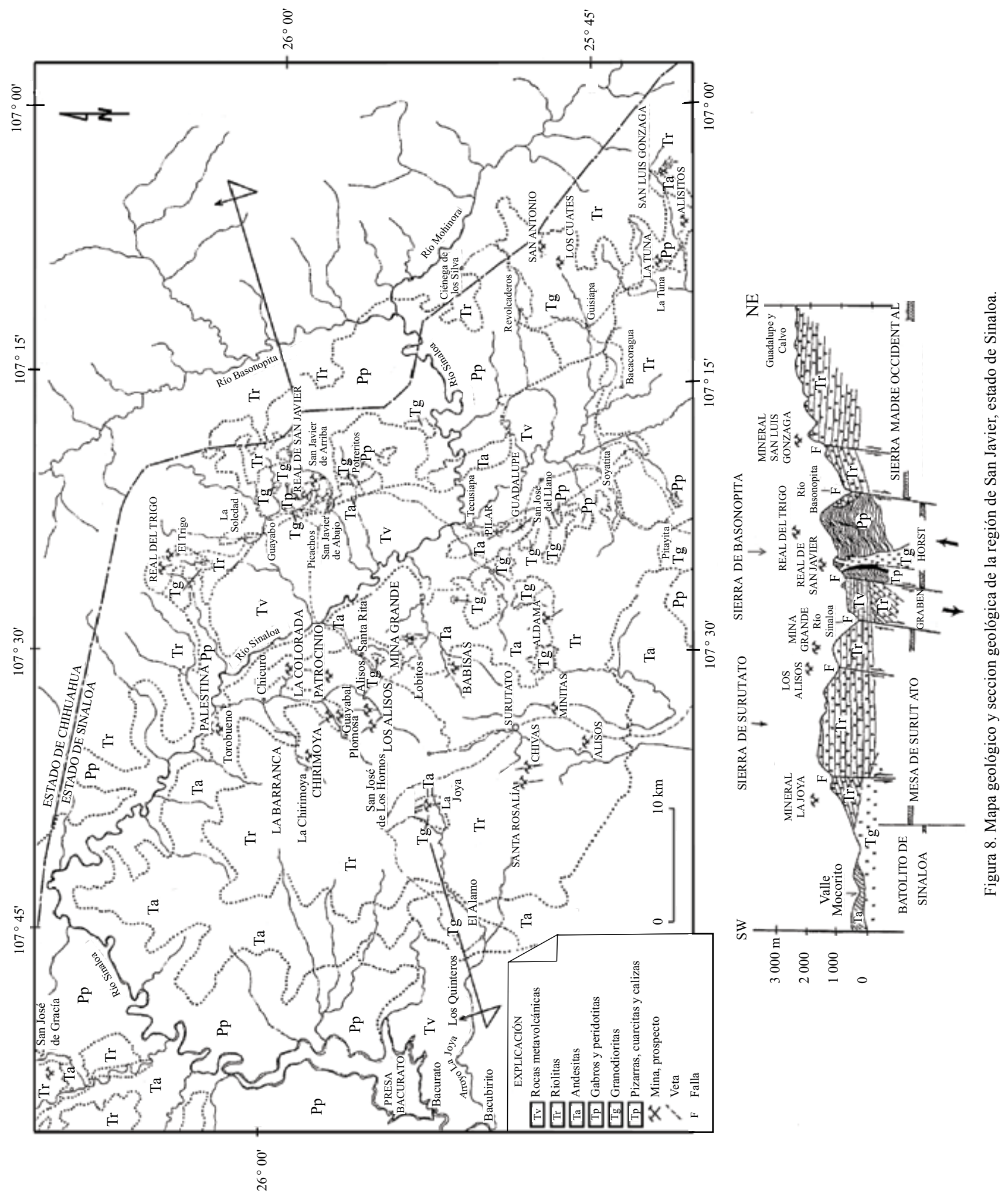


En los complejos UM-M del Triásico SuperiorJurásico Medio (península de Vizcaíno e Islas Margarita y Magdalena), las litologías predominantes son wehrlitas, harzburgitas, clinopiroxenitas, gabronoritas y dioritas formando bloques exóticos en complejos de subducción, originalmente formados en una ofiolita de tipo SSZ. Las alteraciones reconocidas son serpentinización y rodingitización, y la mineralización metálica se encuentra en pods, diseminaciones y bolsadas de cromita, cuerpos irregulares y stockworks de magnesita. Se han reportado anomalías de Os-Ir-Ru en las cromititas (Vatin-Perignon et al., 2000).

Los complejos UM-M del Cretácico Inferior son los más característicos en México, pues constituyen más del $50 \%$ de los mismos, y la litología predominante consiste en: wehrlitas, harzburgitas, clinopiroxenitas de olivino, dunitas, leucogabros, troctolitas, noritas, doleritas, hornblenditas y dioritas. Estas rocas forman cuerpos elongados (por deformación, ya que las serpentinitas son muy plásticas) de tamaño reducido (de $1 \mathrm{~km}^{2}$ a $28 \mathrm{~km}^{2}$ de afloramiento), y generalmente se presentan en posición alóctona, cabalgando a secuencias volcanosedimentarias penecontemporáneas (Delgado-Argote et al., 1992). Su ambiente geotectónico corresponde a ofiolitas (Bacubirito), raíces de arco (Alisitos, Culiacán), en zonas de cizalla (Motozintla), arcos intraoceánicos (San Juan de Otates, Palmar Chico-San Pedro Limón), en complejos de subducción (Las Ollas, Camalotito, El Tamarindo, Loma Baya), o arco intracontinental de corta vida (Cuicatlán-Concepción Pápalo). La alteración predominante en las rocas de los complejos UM-M de México corresponde a serpentinización, esteatización, uralitización, anfibolitización, y en menor proporción, rodingitización. Sus mineralizaciones metálicas asociadas corresponden a diseminaciones de Au-Ni-Co (Alisitos), Fe-Ni-Co-As \pm Au \pm EGP (Culiacán), Cr-Ni (Loma Baya, Camalotito) y pods de ferricromita (Loma Baya). Su mineralización no metálica es serpentina, principalmente antigorita como en Camalotito, Palmar Chico-San Pedro Limón y crisotilo como en CuicatlánConcepción Pápalo.

En estos complejos UM-M, con excepción de Bacubirito, la casi total ausencia de ortopiroxenos evidencía una actividad baja de sílice y alta de Ca. Sus altos contenidos de Fe sugieren una afinidad magmática toleítica de arco (Figura 9), y una alta actividad de $\mathrm{H}_{2} \mathrm{O}$, evidenciada por la abundancia de anfíboles. Ello sugiere que estos complejos son acumulados formados hacia la base de cámaras magmáticas (raíces de arco magmático). El magma madre de estos complejos podría ser de tipo ankaramítico y provendrían de un manto empobrecido en elementos con fuerte carga iónica, bajo condiciones hidratadas, como se pone de manifiesto en los fragmentos de corteza oceánica en Guanajuato (Ortiz-Hernández, 2000). El potencial por EGP de estos depósitos se considera escaso debido a que éstos se concentran como elementos nativos, o en solución sólida dentro de la estructura cristalina de forsterita, sulfuros, y espinelas de cristalización magmática, especialmente Os,
Ir y $\mathrm{Ru}$ en la cromita, magnetita y espinela de $\mathrm{Fe}-\mathrm{Cr}$.

A pesar de que no existe suficiente documentación sobre la geoquímica de roca total de los complejos UM-M analizados en este trabajo, se aprecian altos contenidos en hierro de algunos de ellos (Figura 9). Por otra parte, en la Figura 10 se muestra que esos mismos complejos siguen una tendencia dominada por la cristalización del olivino $\mathrm{u}$ olivino + clinopiroxeno. Esta tendencia consiste en un decremento de $\mathrm{MgO}$ a valores constantes de $\mathrm{CaO} / \mathrm{Al}_{2} \mathrm{O}_{3}$, considerando que parte del $\mathrm{CaO}$ migra en solución durante la serpentinización.

\section{Conclusiones}

Es notable que los complejos UM-M de México se emplazaron en diferentes contextos tectónicos y en terrenos tectonoestratigráficos donde existe basamento precámbrico, paleozoico o triásico. Estos complejos UM-M albergan mineralizaciones metálicas producidas durante la etapa ortomagmática o por removilización, en forma de cuerpos lenticulares alargados o pods de ferricromita, diseminaciones de minerales de $\mathrm{Cu}-\mathrm{Ni}$-Co e indicios de elementos del grupo del platino. La deformación acompañante ha obliterado de igual manera algunos de los rasgos geológicos primarios de las rocas constituyentes de estos depósitos. La cromita se encuentra en diseminaciones o en forma de pods, y es generalmente rica en hierro (ferricromita) en la mayoría de los complejos UM-M analizados. Sus contenidos en $\mathrm{Cr}_{2} \mathrm{O}_{3}$ son en general bajos (cromita de grado refractario) y excepcionalmente alcanzan valores de hasta $48.7 \%$ (cromita de grado metalúrgico) en el prospecto El Tigre (Vizcaíno, Baja California Sur). El Ni se presenta en bajas cantidades en diseminaciones de sulfuros (pentlandita, millerita, bravoita, violarita), arseniuros (niquelina, maucherita, gersdorffita) y silicato (garnierita). El Co se presenta en skutterudita, escorodita y glaucodoto. Los

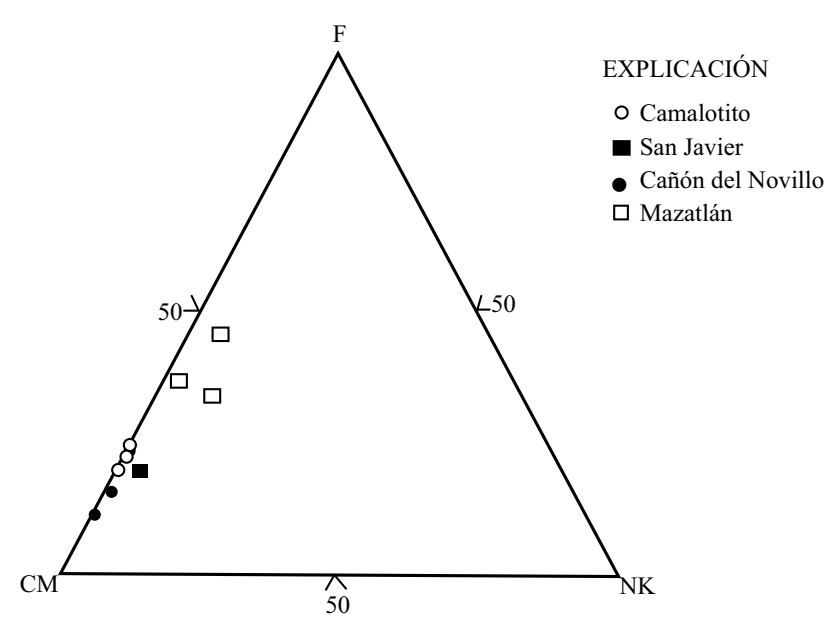

Figura 9. Diagrama F-CM-NK $\left(\mathrm{FeO}^{\mathrm{T}}-\mathrm{CaO}+\mathrm{MgO}-\mathrm{Na}_{2} \mathrm{O}+\mathrm{K}_{2} \mathrm{O}\right)$ de algunos complejos ultramáficos-máficos. 


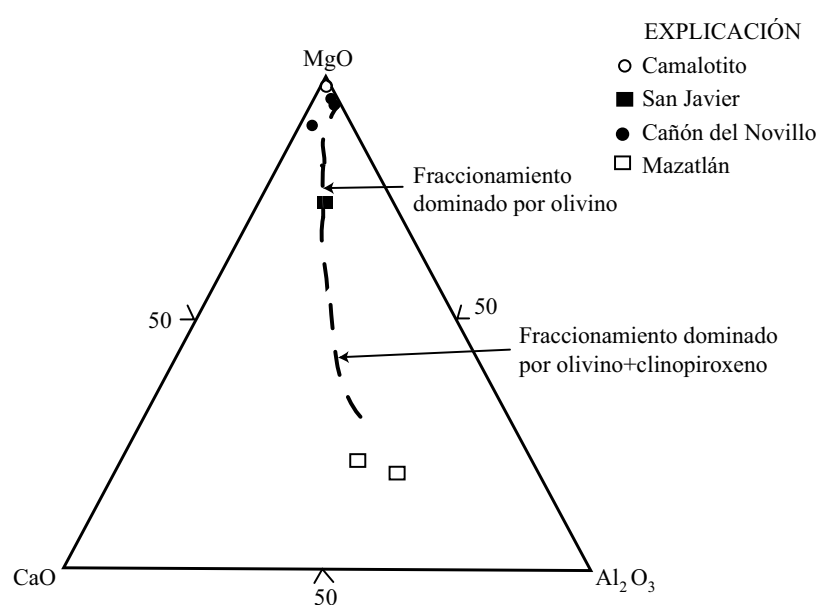

Figura 10. Diagrama $\mathrm{MgO}-\mathrm{CaO}-\mathrm{Al}_{2} \mathrm{O}_{3}$ de algunos complejos ultramáficos-máficos.

mejores prospectos para Ni-Co son los complejos máficos de Culiacán y Alisitos en Sinaloa. El Cu puede presentarse como diseminaciones de calcopirita, pero también como minerales secundarios (crisocola, azurita y malaquita) en vetas terciarias que atraviesan algunos de estos complejos UM-M (Mazatlán). Estos cuerpos también desarrollaron mineralizaciones no metálicas como asbesto, talco y magnesita durante la alteración hidrotermal y/o el metamorfismo regional ulteriores en facies de prehnita-pumpellyita, esquistos verdes, anfibolita, o esquistos azules.

Los EGP pueden encontrarse en asociación a cromititas (como es el caso de Vizcaíno y Tehuitzingo), sulfuros de metales básicos, o a mineralizaciones arsenicales como en el caso del complejo UM-M de Culiacán, donde los valores de platino podrían estar asociados a As en la forma de sperrylita $\left(\mathrm{PtAs}_{2}\right)$. Así, las asociaciones con minerales de As son prospectables por MGP. Además, los depósitos de placer pueden contener aleaciones de hierro y platino (isoferroplatino, $\mathrm{Pt}_{3} \mathrm{Fe}$ ), asociadas a cromititas de cristalización tardía. No debe descartarse la posibilidad de obtener también platino como subproducto de la refinación del $\mathrm{Cu}$, ni de la fundición y refinación de metales base y menas auríferas o concentrados de $\mathrm{Au}$.

Por otra parte, considerando los minerales no metálicos presentes en los complejos UM-M, la antigorita de algunos complejos (p.e. Camalotito en Guerrero), reúne las especificaciones para ser utilizada en la industria siderúrgica como fundente en la producción de arrabio, en la industria agrícola como fertilizante de suelos, e incluso como roca dimensionable o material de ornato. Sólo los complejos UM-M de Cañón del Novillo en Tamaulipas y CuicatlánConcepción Pápalo en Oaxaca han sido explotados por su contenido en crisotilo. El talco ha sido explotado de manera irregular y en pequeña escala (p.e. en San Juan de Otates, Guanajuato), y los depósitos de magnesita de Isla Santa Margarita en Baja California Sur son potencialmente explotables para la manufactura de ladrillos refractarios o material de revoque en hornos.
Además de los veinte complejos UM-M descritos en este trabajo, se conocen depósitos similares como Aramberri en Nuevo León (Núñez-Espinal, 1981) y Macochin en Sinaloa (Mullan, 1978), así como los complejos UM-M de Sonora (Rodríguez-Castañeda et al., 2003) que no han sido completamente estudiados a la fecha, y que son susceptibles de albergar mineralizaciones como las citadas.

\section{Agradecimientos}

Los autores hacen patente su agradecimiento a los árbitros que realizaron la revisión del manuscrito original, el Dr. Antoni Camprubí del Centro de Geociencias de la UNAM, campus Juriquilla, Querétaro, y el Dr. J. A. Proenza de la Universitat de Barcelona, España, quienes contribuyeron en gran medida a mejorar el contenido del texto.

\section{Referencias bibliográficas}

Berger, E., Frot, G., Lehmann, J., Marion, C., Vannier, M., 1982, Un géothermomètre potential très sensible, reposant sur la teneur en silicium des spinelles de paragéneses á olivine: Comptes Rendues de l'Académie des Sciences de Paris, 294 (II), 733-736.

Bonneau, M., 1972, Données nouvelles sur les séries crétacées de la côte pacífique du Mexique: Bulletin de la Societé Géologique de France, 7 (XIV), 55-65.

Bustamante-Yánez, M. A., 1985, Recursos minerales en el estado de Sinaloa: Culiacán, Sinaloa, México: México, Consejo de Recursos Minerales y Gobierno del Estado de Sinaloa, 79 p.

Carballido-Sánchez, E. A., Delgado-Argote, L. A., 1989, Geología del cuerpo serpentínico de Tehuitzingo, estado de Puebla-interpretación preliminar de su emplazamiento: Revista del Instituto de Geología de la Universidad Nacional Autónoma de México, 8 (2), 134-148.

Carfantan, J. C., 1977, La cobijadura de Motozintla, un paleoarco volcánico en Chiapas: Revista del Instituto de Geología de la Universidad Nacional Autónoma de México, 1 (2), 133-137.

Carfantan, J. C., 1984, Evolución estructural del sureste de México: paleogeografía e historia tectónica de las zonas internas mesozoicas: Revista del Instituto de Geología de la Universidad Nacional Autónoma de México, 5, 207-216.

Castro-Leyva, T. J., Delgado-Argote, L. A., García-Abdeslem, J., 2001, Geología y magnetometría del complejo máfico-ultramáfico Puerto Nuevo en el área de San Miguel, península de Vizcaíno, Baja California Sur: GEOS, 21 (1), 3-21.

Cerecero-Luna. M., Serrano-Villar, J. F., Montañés-Díaz de León, C., García-Ruiz, J. M., Rojo-Yáñiz, R., 1984, Informe consolidado del proyecto rocas ultrabásicas (Sinaloa): Culiacán, Sinaloa, México: México DF, México, Consejo de Recursos Minerales, Informe Técnico, 115 p. (no publicado).

Clark, K.F., 1973, Rocas básicas y ultrabásicas en el estado de Sinaloa: Chihuahua, Chihuahua, México, en Memoria de la X Convención de la AIMMGM, 271-281.

Consejo de Recursos Minerales, 1999, Monografía Geológico Minera del estado de Chiapas: Pachuca, Hidalgo, México: México D.F., México, Secretaría de Comercio y Fomento Industrial, Coordinación General de Minería, publicación 20e, 180 p.

Consejo de Recursos Minerales, 2000, Geological-mining monograph of the state of Baja California Sur: Pachuca, Hidalgo, México: México D.F., México, Secretaría de Comercio y Fomento Industrial, Coordinación General de Minería, Publication M-24e, 231 p.

Consejo de Recursos Minerales, 2002, Boletín Técnico COREMI, proyecto Cañón del Novillo: Pachuca, Hidalgo, México: México 
D.F., México, Secretaría de Comercio y Fomento Industrial, Coordinación General de Minería, 49, 28-30.

Corona-Esquivel, R., 1981, Estratigrafía de la región de OlinaláTecocoyunca, noreste del Estado de Guerrero: Revista del Instituto de Geología de la Universidad Nacional Autónoma de México, 5, 17-24.

de Cserna, Z., Graf, J. L. Jr., Ortega-Gutiérrez, F., 1977, Alóctono del Paleozoico inferior en la región de Ciudad Victoria, estado de Tamaulipas: Revista del Instituto de Geología de la Universidad Nacional Autónoma de México, 1, 33-43.

Delgado-Argote, L. A., 1986, Síntesis geológica de áreas máficas y ultramáficas de México y su potencial económico: Boletín de Mineralogía, 2 (1), 21-40.

Delgado-Argote, L. A., Morales-Velázquez, J. E., 1984, Rasgos geológicos y económicos del complejo básico-ultrabásico de El Tamarindo, Guerrero: Geomimet, 128, 81-96.

Delgado-Argote, L. A., 1988, Geología preliminar de la secuencia volcanosedimentaria y serpentinitas asociadas del Jurásico (?) del área de Cuicatlán-Concepción Pápalo, Oaxaca: Revista del Instituto de Geología de la Universidad Nacional Autónoma de México, 7 (2), 127-135.

Delgado-Argote, L. A., 1989, Regional implications of the JurassicCretaceous volcanosedimentary Cuicateco terrane, Oaxaca, Mexico: Geofísica Internacional, 28 (5), 939-973.

Delgado-Argote, L. A., Rubinovich-Kogan R., Gasca-Durán, A., 1986, Descripción preliminar de la geología y mecánica de emplazamiento del complejo ultrabásico del Cretácico de Loma Baya, Guerrero, México: Geofísica Internacional, 25 (4), 537-558.

Delgado-Argote, L. A., López, M. M., York, D., Hall, C.M., 1992, Geologic framework and geochronology of ultramafic complexes of southern Mexico: Canadian Journal of Earth Sciences, 29, 1590-1604

Elías-Herrera, M., Sánchez-Zavala, J. L., Macías-Romo, C., 2000, Geologic and geochronologic data from the Guerrero terrane in the Tejupilco area, southern Mexico: new constraints on its tectonic interpretation: Journal of South American Earth Sciences, 13 (45), 355-375.

Freydier, C., Lapierre, H., Ruiz, J., Tardy, M., Martínez-Reyes, J., Coulon, C., 2000, The Early Cretaceous Arperos basin: an oceanic domain dividing the Guerrero arc from nuclear Mexico evidenced by the geochemistry of the lavas and sediments: Journal of South American Earth Sciences, 13 (4-5), 325-336.

González-Reyna, J., 1946, Los depósitos de magnesita de la porción central de Isla Margarita, Baja California: México, Comité Directivo sobre la Investigación de los Recursos Minerales de México, 10, $31 \mathrm{p}$.

Hernández-Velázquez, J. Herrera-Martínez, R. A., Jiménez-Mendoza, J. L., Madrigal-Bulnes, A., Mojica-Mondragón, A., MonsalvoArellanos, J., 1990, Geología y prospección minera del área Palmar Chico, municipio de Amatepec, México: México D.F., México, Universidad Nacional Autónoma de México, Facultad de Ingeniería, tesis profesional (inédita), $120 \mathrm{p}$.

Kelemen, P.B., Dick, H.J.B., Quick, J.E., 1992, Formation of harzburgite by pervasive melt/rock reaction in the upper mantle: Nature, 358 , 635-641.

Kimbrough, D.L., 1985, Tectonostratigraphic terranes of the Vizcaino peninsula and Cedros and San Benito islands, Baja California, Mexico: Earth Sciences, 285-297.

Lapierre, H., Ortiz-Hernández, E., Abouchami, W., Monod, O., Coulon, C., Zimmermann, J. L., 1992, A crustal section of an intraoceanic island arc: the Late Jurassic-Early Cretaceous Guanajuato magmatic sequence (central Mexico): Earth and Planetary Science Letters, $108,61-77$.

Meza-Figueroa, D., Ruiz, J., Talavera-Mendoza, O., Ortega-Gutiérrez, F., 2003, Tectonometamorphic evolution of the Acatlan complex eclogites (southern Mexico): Canadian Journal of Earth Sciences, $40,27-44$.

Moore, T.E., 1976, Structure and petrology of the sierra de San Andrés ophiolite, Vizcaino peninsula, Baja California Sur, México:
San Diego, USA, San Diego State University, tesis de maestría (inédita), $80 \mathrm{p}$.

Morales-Velázquez, J. E., Ortiz-Hernández L. E., Núñez-Espinal, J., 1985, Yacimientos de serpentina en la localidad ultrabásica de Camalotito, municipio de Petatlán, Guerrero: Geomimet, 136, 20-37.

Mullan, H.S., 1978, Evolution of part of the Nevadan orogen in northwestern Mexico: Bulletin of the Geological Society of America, 89, 1175-1188.

Mullan, H.S., Bussell, M.A., 1977, The basic rock series in batholithic associations: Geological Magazine, 114, 265-280.

Núñez-Espinal, J., 1981, Reconocimiento geológico en algunas localidades ultrabásicas prospectando por cromo y níquel en la República Mexicana: México D.F., México, Universidad Nacional Autónoma de México, Facultad de Ingeniería, Tesis de Licenciatura (inédita), $79 \mathrm{p}$.

Núñez-Espinal, J., Salgado-Terán, V., Segura-García, L., 1981, Reconocimiento geológico del área cromífera de Papanoa-Petatlán, Guerrero: Geomimet, 114, 71-91.

Ortega-Gutiérrez, F., 1978, Estratigrafía del Complejo Acatlán en la Mixteca Baja, estados de Puebla y Oaxaca: Revista del Instituto de Geología de la Universidad Nacional Autónoma de México, $2,112-131$.

Ortega-Gutiérrez, F., Prieto-Vélez, R., Zúñiga, Y., Flores, S., 1979, Una secuencia volcano-plutónica-sedimentaria cretácica en el norte de Sinaloa; ¿un complejo ofiolítico?: Revista del Instituto de Geología de la Universidad Nacional Autónoma de México, 3, 1-8.

Ortega-Gutiérrez, F., Elías-Herrera, M., Reyes, M., Macías, C., López, R.,1999, Late Ordovician-Early Silurian continental collisional orogeny in southern Mexico and its bearing on Godwana-Laurentia connections: Geology, 27, 719-722.

Ortega-Rivera, A., 2003, Geochronological constraints on the tectonic history of the Peninsular Ranges batholith of Alta and Baja California: tectonic implications for western Mexico, in Johnson, S. E., Paterson, S. R., Fletcher, J. M, Girty, G. H., Kimbrough, D. L, Martin-Barajas, A. (eds.), Tectonic Evolution of northwestern Mexico and southwestern United States: USA, Geological Society of America, Special Paper 374, 297-336.

Ortiz-Hernández, L. E., 1984, Paragénesis y alteración hidrotermal en el prospecto cromo-niquelífero de Loma Baya, Petatlán, Gro: Geomimet, 130, 23-43.

Ortiz-Hernández, L. E., 2000, An arc ankaramite occurrence in central Mexico: Revista Mexicana de Ciencias Geológicas, 17 (1), 34-44.

Ortiz-Hernández, L. E, Lapierre, H., 1991, Field, petrological and geochemical evidences for the intra-oceanic environment of the Upper Jurassic-Early Cretaceous Palmar Chico-Arcelia arc sequence (southern Mexico): Pachuca, Hidalgo, México, Convención sobre la evolución geológica de México-Primer congreso mexicano de Mineralogía, Memoria, 144-146.

Ortiz-Hernández, L.E., Calvet, Ph., Chiodi, M., Yáñez-Mondragón, F., 1989, Afinidad magmática y procesos metalogenéticos del cortejo magmático mesozoico de la sierra de Guanajuato, México central: Acapulco, Guerrero, México: Memorias Técnicas de la XVIII Convención de la AIMMGM, 109-125.

Pantoja-Alor, J., Rincón-Orta, C., Fries, C. Jr., Silver, L.T., SolorioMunguía, J., 1974, Contribuciones a la geocronología de Chiapas: Boletín de la Asociación Mexicana de Geólogos Petroleros, 26, 207-223.

Pearce, J.A., Lippard, S.J., Roberts, S., 1985, Characteristics and tectonic significance of supra-subduction zone ophiolites, in Kokelaar, B.P., Howell, M.F. (eds.), Marginal basin geology. Volcanic and associated sedimentary and tectonic processes in modern and ancient marginal basins: The Geological Society of London. Blackwell Publishing, 77-94.

Proenza, J. A., Ortega-Gutiérrez, F., Camprubí, A., Tritlla, J., ElíasHerrera, M., Reyes-Salas, M., 2004, Paleozoic serpentinite-enclosed chromitites from Tehuitzingo (Acatlán Complex, southern Mexico): a petrological and mineralogical study: South American Journal of Earth Sciences, 16 (8), 649-666.

Radelli, L., 1994, Geology of the ultrabasic and basic rocks of the 
Vizcaino Peninsula, southern Baja California, Mexico: Boletín del Departamento de Geología de la Universidad de Sonora, 11 (1), 191-210.

Radelli, L., 1995, Geology and origin of the basic and ultrabasic rocks of the Vizcaino, southern Baja California, Mexico, in Tercera Reunión Internacional sobre la geología de la península de Baja California, La Paz, B.C.S., México, Universidad Autónoma de Baja California Sur, Sociedad Geológica Peninsular, 164-169.

Ramírez, R. C., 1975, Reconocimiento geológico de las zonas metamórficas al poniente de Ciudad Victoria, Tamps.: México, D.F., Consejo de Recursos Naturales No Renovables e Instituto de Geología de la Universidad Nacional Autónoma de México, Informe Técnico, 86 p. (no publicado).

Ramírez, L. J. C., 1988, Geología del yacimiento de asbesto Pegaso, Concepción Pápalo, Cuicatlán, Oaxaca, in Salas, G.P. (ed.), Geología Económica de México, Fondo de Cultura Económica, $1^{\mathrm{a}}$ edición, 437-445.

Rangin, C, 1976, Le complexe ophiolitique de Basse Californie: une paléocrôute océanique écaillée (péninsule de Vizcaino, Baja California, Mexique): Bulletin de la Société Géologique de France, 18 (VI), 1677-1685.

Rangin, C., 1977, Sur un trait majeur de la bordure continentale pacifique: le dispositif franciscain en Basse Californie (Mexique): Compte Rendue sommaire de la Société Géologique de France, 4, 227-230.

Rock, N.M.S., 1991, Lamprophyres: New York, Glasgow and London, Blackie \& Sons Ltd., 285 p.

Rodríguez-Castañeda, J. L., Rodríguez-Torres, R., Almazán-Vázquez, E., 2003, An inventory of mafic and ultramafic rocks of cordilleran Proterozoic basament (?) in northern Sonora, Mexico: preliminary results: Puerto Vallarta, Jalisco, México, 99th Annual Meeting Cordilleran Section, Geological Society of America Abstracts with Programs, Session No. 40-5 (abstract).

Salas, G.P., 1975, Carta y provincias metalogenéticas de la República Mexicana. Consejo de Recursos Minerales, publicación 21E, $2^{\mathrm{a}}$ edición, $200 \mathrm{p}$.

Salas-Pizá, G., 1970, Evaluación geológico-minera del distrito asbestífero del Cañón del Novillo, Ciudad Victoria, Tamaulipas: México, D.F., Consejo de Recursos Naturales No Renovables, 71, 20 p.

Sedlock, R. L., 1988, Tectonic setting of blueschist and island-arc terranes of west-central Baja California, Mexico: Geology, 16, 623-626.

Sedlock, R. L., Ortega-Gutiérrez, F., Speed, R. C., 1993, Tectonostratigraphic terranes and tectonic evolution of Mexico: Geological Society of America, Special Paper 278, 153.
Servais, M., Rojo-Yáñiz, R., Colorado-Liévano, D., 1982, Estudio de las rocas básicas y ultrabásicas de Sinaloa y Guanajuato: postulación de un paleogolfo de Baja California y de una digitación tethysiana en México central: Geomimet, 115, 53-71.

Servais, M., Monod, O., Kienast, J. R., Chiodi, M., 1985, Descubrimiento de kimberlitas en Mexico: área San Javier, municipio de Badiraguato, estado de Sinaloa: Mazatlán, Sinaloa, México, in Memorias Técnicas de la XVI Convención de la AIMMGM, 26 p.

Servais, M., Cuevas-Pérez, E., Monod, O., 1986, Une section de Sinaloa à San Luis Potosí: nouvelle approche de l'évolution du Mexique nord-occidental: Bulletin de la Societé Géologique de France, 8 (II), 1033-1047.

Talavera-Mendoza, O., 1993, Les formations orogéniques mésozoïques de Guerrero (Mexique méridional). Contribution à la connaisance de l'évolution géodynamique des cordillères mexicaines.: Grenoble, Francia, Université Joseph Fourier I, Thèse de doctorat (tesis doctoral, inédita), $462 \mathrm{p}$.

Talavera, M. O., Guerrero, S. M., 2000, Geochemistry and isotopic composition of the Guerrero Terrane (western Mexico): implications for the tectono-magmatic evolution of southwestern North America during the Late Mesozoic: Journal of South American Earth Sciences, 13 (4-5), 297-324.

Talavera-Mendoza, O., 2001, Mélanges in southern Mexico: geochemistry and metamorphism of Las Ollas complex (Guerrero terrane): Canadian Journal of Earth Sciences 37, 1309-1320.

Vatin-Perignon, N., Amossé, J., Radelli, L., Keller, F., Castro, L.T., 2000, Platinum group element behaviour and thermo-chemical constraints in the ultrabasic-basic complex of the Vizcaino peninsula, Baja California Sur, Mexico: Lithos, 53, 59-80.

Zaccarini, F, Proenza, J.A., Ortega-Gutiérrez, F., Garuti, G., 2005, Platinum-group minerals in ophiolitic chromitites from Tehuitzingo (Acatlán complex, southern Mexico): implications for postmagmatic modification: Mineralogy and Petrology, 84, 147-168.

Manuscrito recibido: Enero 21, 2005

Manuscrito corregido recibido: Septiembre 26, 2005

Manuscrito aceptado: Junio 29, 2006 